\title{
Measurements and Modeling of Thermal Conductivity of Recycled Aggregates from Concrete, Clay Brick, and Their Mixtures with Autoclaved Aerated Concrete Grains
}

\author{
Hong Nam Thai ${ }^{1,2, * \mathbb{D}}$, Ken Kawamoto ${ }^{1,3} \mathbb{D}^{\mathbb{D}}$, Hoang Giang Nguyen ${ }^{3}$, Toshihiro Sakaki ${ }^{4}$, Toshiko Komatsu ${ }^{1}$ \\ and Per Moldrup 5
}

check for updates

Citation: Thai, H.N.; Kawamoto, K.; Nguyen, H.G.; Sakaki, T.; Komatsu, T.; Moldrup, P. Measurements and Modeling of Thermal Conductivity of Recycled Aggregates from Concrete, Clay Brick, and Their Mixtures with Autoclaved Aerated Concrete Grains. Sustainability 2022, 14, 2417. https:// doi.org/10.3390/su14042417

Academic Editor: Cinzia Buratti

Received: 18 January 2022

Accepted: 16 February 2022

Published: 20 February 2022

Publisher's Note: MDPI stays neutral with regard to jurisdictional claims in published maps and institutional affiliations.

Copyright: (c) 2022 by the authors. Licensee MDPI, Basel, Switzerland. This article is an open access article distributed under the terms and conditions of the Creative Commons Attribution (CC BY) license (https:// creativecommons.org/licenses/by/ $4.0 /)$.
1 Graduate School of Science and Engineering, Saitama University, Saitama 338-8570, Japan; kawamoto@mail.saitama-u.ac.jp (K.K.); komatsu@mail.saitama-u.ac.jp (T.K.)

2 Faculty of Bridges and Roads, Hanoi University of Civil Engineering, Hai Ba Trung, Hanoi 11616, Vietnam

3 Faculty of Building and Industrial Construction, Hanoi University of Civil Engineering, Hai Ba Trung, Hanoi 11616, Vietnam; giangnh@huce.edu.vn

4 Environmental Science and Engineering Consulting LLC, Nishinomiya-shi 662-0842, Japan; tsakaki.ese@gmail.com

5 Department of the Built Environment, Aalborg University, DK-9220 Aalborg, Denmark; pmol@build.aau.dk

* Correspondence: namth@huce.edu.vn

\begin{abstract}
Cool road pavements contribute to mitigating urban heat islands. To evaluate the heat balance in paved surfaces and to select appropriate road construction materials that help suppress heat islands, an accurate understanding of heat transport parameters such as thermal conductivity $(\lambda)$ and heat capacity $(H C)$ is important. Recycled aggregates from construction and demolition waste, including scrap construction materials and industrial by-products, are often used for road construction; however, $\lambda$ and $H C$ of recycled aggregates especially for roadbeds are not fully understood. This study involved a series of laboratory tests to measure $\lambda$ and $H C$ of recycled concrete and clay brick aggregates $(<40 \mathrm{~mm})$ and their mixtures with autoclaved aerated concrete grains $(<2 \mathrm{~mm})$ under varied moisture conditions. The measured $\lambda$ and $H C$ increased with increasing volumetric water content $(\theta)$. Closed-form models for estimating $\lambda(\theta)$ were proposed using normalized thermal conductivity $\left(\lambda_{e}\right)$ and effective saturation $\left(S_{e}\right)$. The new $\lambda_{e}\left(S_{e}\right)$ models performed well for the measured data compared to previously proposed models and would be useful to evaluate $\lambda$ of recycled aggregates for roadbed materials.
\end{abstract}

Keywords: thermal conductivity; heat capacity; construction and demolition waste (CDW); autoclaved aerated concrete (AAC); recycled aggregates; urban heat islands

\section{Introduction}

Natural resources have been always exploited in human activities, and the construction industry is one of the industries that uses the most natural resources [1]. The unsustainable exploitation of natural resources leads to a series of adverse consequences such as environmental degradation, climate change, and depletion of natural resources. The construction industry also releases large amounts of solid waste into the environment during the processes of construction and demolition [1]. In developing countries such as those in Southeast Asia, along with economic development, the urbanization and industrialization has led to significant generation of construction and demolition waste (CDW), scrap construction materials (e.g., autoclaved aerated concrete (AAC)), and industrial by-products such as steel slag and coal ash [2,3]. While in the developed countries such as Japan, the USA, Australia, and members of the EU, most of the CDW, scrap construction materials, and industrial by-products are being recycled [4], in the developing countries, the percentage of recycled materials is very low. For example, in Vietnam, only $1-2 \%$ of CDW is recycled [5]. Instead, CDW is usually dumped at landfills without any treatment or illegally 
dumped in ponds, canals, and public areas [1,2,6]. Therefore, promoting the use of recycled materials from CDW, scrap construction materials, and industrial by-products in developing countries is essential to ensure environmental safety and reduce the consumption of natural materials.

Thermal conductivity $(\lambda)$ and thermal capacity $(H C)$ of materials play important roles in a variety of engineering applications $[7,8]$. For example, in the field of civil construction, materials with low thermal conductivity are often selected as insulating materials for walls and roofs. In contrast, the backfill materials or soils surrounding power cables must have a high thermal conductivity for the generated heat to dissipate to ensure that the cables are not thermally overloaded [7]. To mitigate the formation of urban heat islands and to construct cooling road pavements, low thermal conductivity, high porosity, and good water retention materials are especially effective $[9,10]$. The surface layer along with the road base layers participate in the heat transfer process of the pavement structure. Many previous studies have investigated CDW, scrap construction materials, and industrial by-products as road base and subbase materials; however, most of them were focused largely on the mechanical properties, hydraulic conductivity, and gas transport parameters [3,11-14]. To date, few studies have investigated the thermal conductivity and heat capacity of recycled aggregates of roadbed materials from $\mathrm{CDW}$, scrap construction materials, and industrial by-products.

The objectives of this study were, for recycled aggregates from concrete, clay brick, and their mixtures with autoclaved aerated concrete grains, that are often used as road base materials: (i) to evaluate the thermal conductivity and heat capacity under varied moisture conditions and (ii) to develop new models suitable for thermal conductivity of these materials.

\section{Materials and Methods}

\subsection{Materials}

CDW was collected from the Thanh Tri landfill, Hanoi, Vietnam $\left(20^{\circ} 59^{\prime} 21.6^{\prime \prime} \mathrm{N}\right.$, $105^{\circ} 53^{\prime} 58.1^{\prime \prime}$ E), and AAC scrap was obtained from the Viglacera Joint Stock Company in Bac Ninh province, Vietnam $\left(21^{\circ} 11^{\prime} 50.8^{\prime \prime} \mathrm{N}, 106^{\circ} 00^{\prime} 42.8^{\prime \prime} \mathrm{E}\right)$. All materials were shipped from Vietnam to Japan then crushed, sieved, and graded to prepare samples for a series of laboratory tests. Photographs of the samples tested in this study are shown in Figure A1. Seven test samples were prepared by blending recycled concrete $(\mathrm{RC})$ or recycled clay brick (RCB) with different proportions of AAC, i.e., RC100\%, RCB100\%, AAC100\%, RC $80 \%+$ $\mathrm{AAC} 20 \%, \mathrm{RC} 60 \%+\mathrm{AAC} 40 \%, \mathrm{RCB} 80 \%$ + AAC20\%, and $\mathrm{RCB} 60 \%$ + AAC $40 \%$. The basic physical properties of the tested materials are given in Table 1. AAC is a material with high water absorption, and mixing AAC with RC or RCB is expected to improve the water retention property of RC or RCB mixtures compared to single materials of RC or RCB. The particle size distributions (PSDs) for the tested samples are shown in Figure 1. The upper and lower boundaries of PSDs for road base materials prescribed in the Vietnam national standards TCVN 8859:2011 [15] and TCVN 8857:2011 [16] are also plotted in the figure.

Table 1. Basic physical properties of tested materials.

\begin{tabular}{|c|c|c|c|c|c|c|c|}
\hline \multirow[b]{2}{*}{$\begin{array}{c}\text { Tested } \\
\text { Materials }\end{array}$} & \multirow{2}{*}{$\begin{array}{c}\rho_{\mathrm{s}} \\
\mathrm{kg} \mathrm{m}^{-3}\end{array}$} & \multirow{2}{*}{$\begin{array}{c}w_{\mathrm{AD}} \\
\%\end{array}$} & \multicolumn{2}{|c|}{$w_{a b s}(\%)$} & \multicolumn{2}{|c|}{$\theta_{a b s}\left(\mathrm{~m}^{3} \mathrm{~m}^{-3}\right)$} & \multirow{2}{*}{$\begin{array}{c}\text { LA } \\
\%\end{array}$} \\
\hline & & & $\begin{array}{l}\text { Fine Aggregate } \\
(<4.75 \mathrm{~mm})\end{array}$ & $\begin{array}{l}\text { Coarse Aggregate } \\
\quad(\geq 4.75 \mathrm{~mm})\end{array}$ & $\begin{array}{c}\text { Fine Aggregate } \\
(<4.75 \mathrm{~mm})\end{array}$ & $\begin{array}{l}\text { Coarse Aggregate } \\
(\geq 4.75 \mathrm{~mm})\end{array}$ & \\
\hline $\mathrm{RC}$ & 2630 & 0.85 & 8.5 & 5.2 & 0.06 & 0.06 & 38.0 \\
\hline $\mathrm{RCB}$ & 2640 & 0.34 & 14 & 13 & 0.09 & 0.13 & 45.6 \\
\hline AAC & 2510 & 2.07 & 61 & - & 0.50 & - & 55.6 \\
\hline
\end{tabular}




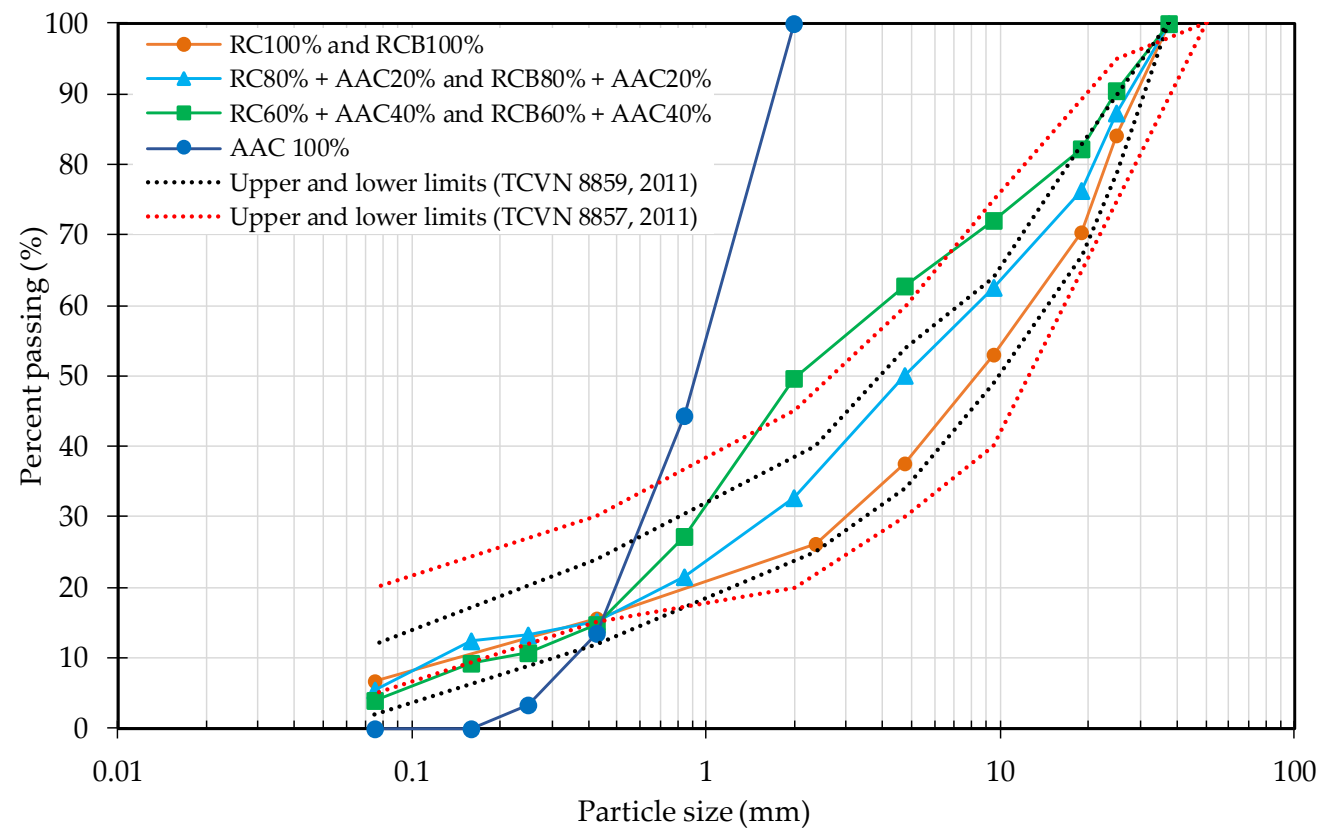

Figure 1. Particle size distributions (PSDs) of tested samples in this study. The upper and lower boundaries of PSD for road base materials prescribed in TCVN 8859:2011 and TCVN 8857:2011, respectively, are indicated by dotted lines.

\subsection{Testing Methods}

\subsubsection{Preparation of the Samples}

The flowchart of sample preparation and measurements is shown in Figure 2. The crushed/sieved/graded samples were mixed at the above-mentioned proportions and compacted following the modified Proctor compaction method described in TCVN 12790:2020 [17] and ASTM D 1557:2012 [18]. The compaction was conducted in a cylindrical mold with an inner diameter of $150 \mathrm{~mm}$ and height of $120 \mathrm{~mm}$ by using a rammer with a weight of $4.54 \mathrm{~kg}$, falling from a height of $457 \mathrm{~mm}$. There were five compacted layers in each sample, and 56 blows were applied per layer (compaction energy $\sim 2700 \mathrm{~kJ} \mathrm{~m}^{-3}$ ). The dry density and total porosity of the tested samples are shown in Table 2.

Sample preparations and measurements

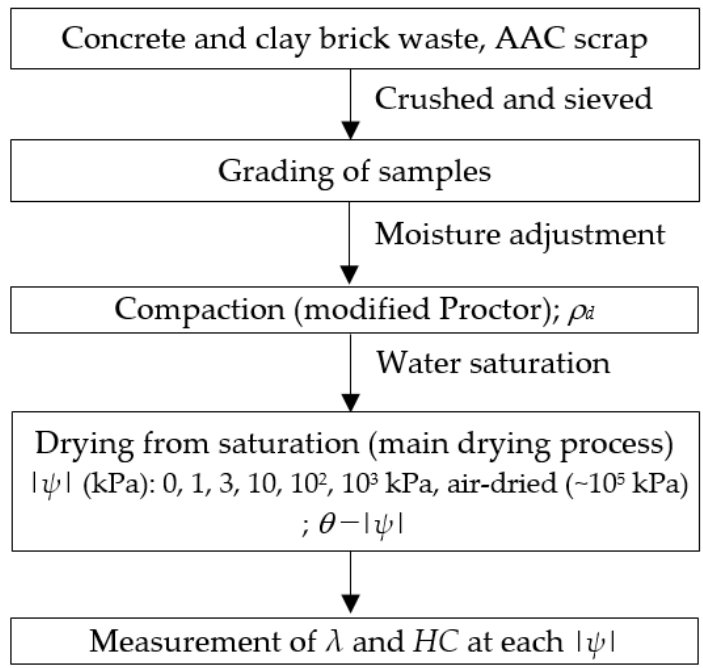

Figure 2. Flowchart of sample preparations and measurements. 
Table 2. Dry density and total porosity of the tested samples.

\begin{tabular}{|c|c|c|c|c|c|}
\hline \multirow{2}{*}{ Tested Samples } & \multicolumn{3}{|c|}{ Percentage in Mixture (\%) } & \multirow{2}{*}{$\begin{array}{c}\rho_{d} \\
\left(\mathrm{~kg} \mathrm{~m}^{-3}\right)\end{array}$} & \multirow{2}{*}{$\begin{array}{c}\phi \\
\left(\mathrm{m}^{3} \mathrm{~m}^{-3}\right)\end{array}$} \\
\hline & RC & RCB & AAC & & \\
\hline $\mathrm{RC} 100 \%$ & 100 & 0 & 0 & 1980 & 0.24 \\
\hline $\mathrm{RC} 80 \%+\mathrm{AAC} 20 \%$ & 80 & 0 & 20 & 1560 & 0.42 \\
\hline $\mathrm{RC} 60 \%+\mathrm{AAC} 40 \%$ & 60 & 0 & 40 & 1260 & 0.52 \\
\hline RCB100\% & 0 & 100 & 0 & 1650 & 0.38 \\
\hline $\mathrm{RCB} 80 \%+\mathrm{AAC} 20 \%$ & 0 & 80 & 20 & 1410 & 0.47 \\
\hline $\mathrm{RCB} 60 \%+\mathrm{AAC} 40 \%$ & 0 & 60 & 40 & 1150 & 0.54 \\
\hline AAC $100 \%$ & 0 & 0 & 100 & 820 & 0.70 \\
\hline
\end{tabular}

\subsubsection{Water Retention Curve Measurement}

After compaction, the samples were saturated with water, and then the water content was reduced by stepwise drainage at different water potential energies $(|\psi|, \mathrm{kPa})$. Two different methods were used to apply different $|\psi|$, i.e., a hanging-water column method was used for lower $|\psi|$ (i.e., 1 and $3 \mathrm{kPa}$ ), and a pressure chamber method was used for higher $|\psi|$ (i.e., 10, 100, and $1000 \mathrm{kPa}$ ). At the end of the drying process, the samples were placed in an oven and dried at 105 degrees to the highest $|\psi|(>1000 \mathrm{kPa})$. After a few days, the dried samples were taken out of the oven and put into a temperature-controlled room for about a week. Then, $|\psi|$ was measured using a dewpoint potential meter (WP4-T, Decagon Devices Inc., Pullman, WA, USA). At each $|\psi|$ value, $\lambda$ and HC of samples were measured as described below.

The water retention curves (WRCs) were fitted by using the van Genuchten model (the unimodal model) [19] or the Durner model (the bimodal model) [20] as Equations (1) and (2), respectively. The van Genuchten model represents the WRCs of the soils having a homogeneous pore structure, while that of Durner represents the WRCs of the soils with a heterogeneous pore structure [21].

$$
\begin{gathered}
S_{e}=\frac{\theta-\theta_{r}}{\theta_{s}-\theta_{r}}=\frac{1}{\left[1+(\alpha|\psi|)^{n}\right]^{m}} \\
S_{e}=\frac{\theta-\theta_{r}}{\theta_{s}-\theta_{r}}=\sum_{i=1}^{k} w_{i}\left[\frac{1}{1+\left(\alpha_{i}|\psi|\right)^{n_{i}}}\right]^{m_{i}}
\end{gathered}
$$

where $\theta\left(\mathrm{m}^{3} \mathrm{~m}^{-3}\right), \theta_{r}\left(\mathrm{~m}^{3} \mathrm{~m}^{-3}\right)$, and $\theta_{s}\left(\mathrm{~m}^{3} \mathrm{~m}^{-3}\right)$ are the volumetric water content, residual volumetric water content, and the saturated volumetric water content, respectively; $k$ is the number of the peak pore size density or subsystems which form the total pore size distribution; $w_{i}$ represents the sub-curve weighting factors; and $\alpha_{i}, n_{i}$, and $m_{i}$ are the parameters of the sub-curves $\left(m_{i}=1-1 / n_{i}\right)$ that indicate fitted parameters. The equivalent pore size distributions of the tested samples were calculated by using the equation which was defined by Durner [20]:

$$
\frac{\mathrm{d} \theta(r)}{\mathrm{d} \log r}=\frac{\mathrm{d}|\psi|}{\mathrm{d} \log |\psi|} \frac{\mathrm{d} \theta(\psi)}{\mathrm{d}|\psi|}=[\ln (10)]|\psi| C^{*}
$$

where $r(\mu \mathrm{m})$ is the equivalent pore radius $\left(r=1500 /|\psi|\right.$; [22]), and $C^{*}$ is the specific moisture capacity $\left(C^{*}=\mathrm{d} \theta / \mathrm{d} \psi\right)$.

The WRCs and pore size distributions of tested samples are shown in Figure 3 with the fitted parameters for WRCs shown in Table 3. While the WRCs of RC100\% and RCB100\% samples were fitted well to the unimodal model [19], the WRCs of other samples were fitted well to the bimodal model [20]. This means that RC100\% and RCB100\% are samples with homogeneous pore structure, while other samples have heterogeneous pore structure due to the presence of AAC as high porosity material, including pores of different sizes $[23,24]$. The WRCs of tested samples showed that the saturated volumetric water content $\left(\theta_{S}\right)$ increased with the increased proportion of AAC grains for both blended RC and RCB 
samples, i.e., the $\theta_{s}$ values of samples with $20 \%$ and $40 \%$ blended AAC were 1.8 to 2.2 times higher than those of the single material for RC mixtures and 1.2 to 1.4 times higher than those of the single material for RCB mixtures. This indicated that the water retention capacities of RC and RCB were improved by blending in AAC grains as expected above. In addition, in air-dried conditions, tested samples retained a high residual volumetric water content $\left(\theta_{r}\right)$. This may be because tested materials, which were compacted before measurement, had high water absorption capacity. Compacted samples are usually very dense and contain many micropores (see Figure $3 b, d$ ), which prevent the movement of water out of the samples under air-dried conditions.
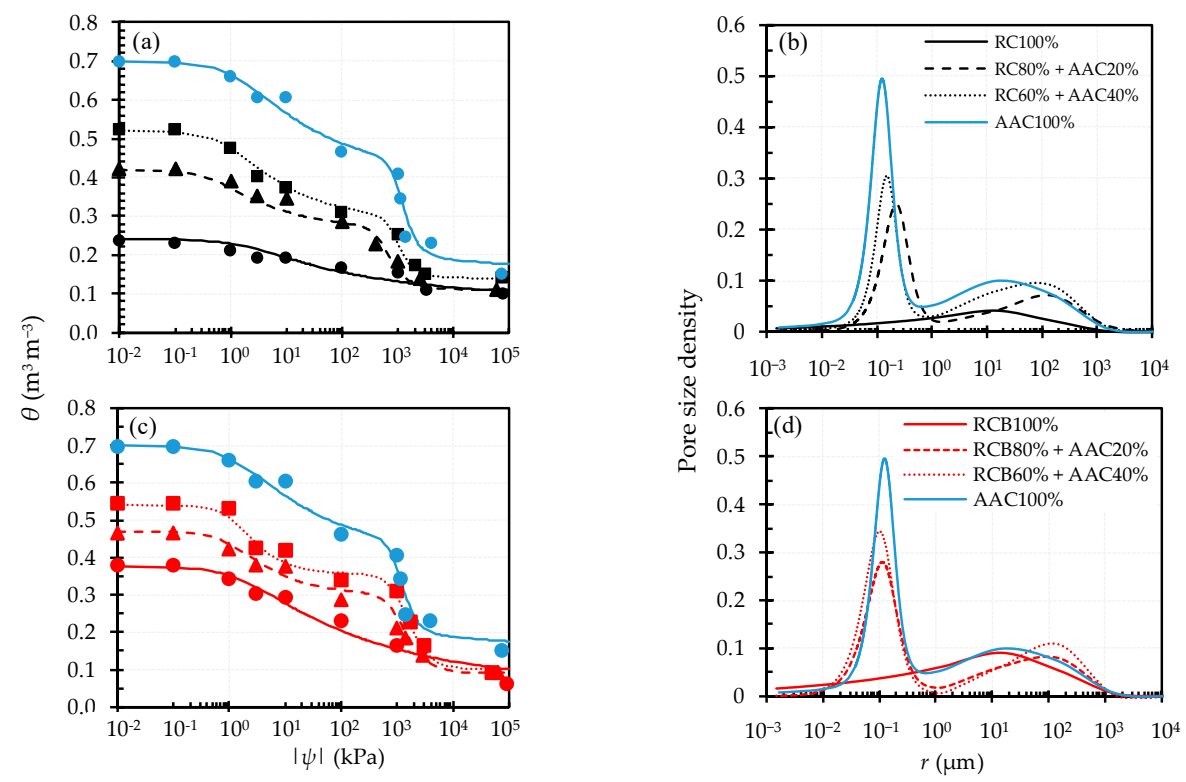

- $\mathrm{RC} 100 \% \triangle \mathrm{RC} 80 \%+\mathrm{AAC} 20 \%-\mathrm{RC} 60 \%+\mathrm{AAC} 40 \% \bullet \mathrm{RCB} 100 \% \triangle \mathrm{RCB} 80 \%+\mathrm{AAC} 20 \%-\mathrm{RCB} 60 \%+\mathrm{AAC} 40 \% \bullet \mathrm{AAC} 100 \%$

Figure 3. Water retention curves (WRCs) (Equations (1) and (2)) and pore size density of tested samples (Equation (3)). (a,b) RC 100\%, RC-AAC mixtures, and AAC100\% and (c,d) RCB100\%, RCB$\mathrm{AAC}$ mixtures, and AAC100\%. Measured values of saturated volumetric water content $\left(\theta_{S}\right)$ were plotted at $|\psi|=10^{-2} \mathrm{kPa}$.

Table 3. Fitting parameters for WRCs for all tested samples (Equations (1) and (2)).

\begin{tabular}{|c|c|c|c|c|c|c|c|c|c|c|}
\hline Tested Samples & $\begin{array}{c}\theta_{s} \\
\left(\mathrm{~m}^{3} \mathrm{~m}^{-3}\right)\end{array}$ & $\begin{array}{c}\theta_{r}^{(a)} \\
\left(m^{3} m^{-3}\right)\end{array}$ & $\alpha_{1}$ & $n_{1}$ & $m_{1}$ & $w_{1}$ & $\alpha_{2}$ & $n_{2}$ & $m_{2}$ & $w_{2}$ \\
\hline $\mathrm{RC} 100 \%$ & 0.24 & 0.09 & 0.06 & 1.2 & 0.17 & - & - & - & - & - \\
\hline $\mathrm{RC} 80 \%+\mathrm{AAC} 20 \%$ & 0.42 & 0.11 & 0.20 & 1.4 & 0.29 & 0.50 & $1.7 \times 10^{-04}$ & 3.1 & 0.68 & 0.50 \\
\hline $\mathrm{RC} 60 \%+\mathrm{AAC} 40 \%$ & 0.52 & 0.14 & 0.11 & 1.4 & 0.28 & 0.61 & $1.1 \times 10^{-04}$ & 3.8 & 0.73 & 0.39 \\
\hline RCB100\% & 0.38 & 0.06 & 0.07 & 1.2 & 0.15 & - & - & - & - & - \\
\hline $\mathrm{RCB} 80 \%+\mathrm{AAC} 20 \%$ & 0.47 & 0.09 & 0.09 & 1.6 & 0.35 & 0.45 & $9.0 \times 10^{-05}$ & 2.7 & 0.63 & 0.55 \\
\hline $\mathrm{RCB} 60 \%+\mathrm{AAC} 40 \%$ & 0.54 & 0.10 & 0.07 & 1.9 & 0.48 & 0.42 & $8.0 \times 10^{-05}$ & 2.8 & 0.64 & 0.58 \\
\hline $\mathrm{AAC} 100 \%$ & 0.70 & 0.16 & 0.08 & 1.3 & 0.22 & 0.56 & $9.0 \times 10^{-05}$ & 3.8 & 0.74 & 0.44 \\
\hline
\end{tabular}

(a) $\theta_{r}$ was assumed to be equal to $\theta_{A D}$.

As shown in the figures, the equivalent pore size distributions of tested samples depend significantly on the proportion of AAC grains. The pore size distribution of the AAC seems more dominant than those of the RC and RCB grains. As a result, the increase in the proportion of AAC grains tends to increase the pore size density of both fine pores (ranging from 0.03 to $1 \mu \mathrm{m}$ ) and large pores (ranging from 5 to $300 \mu \mathrm{m}$ ). 


\subsubsection{Measurement of Thermal Properties}

A variety of methods can be used to measure thermal properties of materials such as needle probe, hot-wire, hot plate, and heat-flow meter, of which needle probe and hot-wire are the widely used methods $[25,26]$.

Figure 4 shows the comparison of thermal conductivity measurements of two samples RC100\% and RCB100\% by two different methods (i.e., needle probe and hot-wire methods). For the needle probe method, the KD2 Pro Thermal Analyzer (Decagon Devices, Pullman, WA, USA) with a dual needle SH-1 sensor (30 mm in length, $1.3 \mathrm{~mm}$ diameter, $6 \mathrm{~mm}$ spacing between two needles) was used. For the hot-wire probe method, a QTM-700 (Kyoto Electronics Manufacturing Co., Ltd., Japan) was used. The thermal conductivities measured by the two methods agreed closely, and the scatterplot points were all within the $95 \%$ confidence interval curves for a 1:1 line as shown by the $t$-test. The needle probe (dual needle probe) method is advantageous because it determines not only $\lambda$ but also $H C$, while the hot-wire method can only determine $\lambda$. Measured HC data of recycled aggregates have been quite limited in past studies. Although the development of the models focused only on the $\lambda-\theta$ relationships, we took advantage of the simultaneous $\lambda$ and $H C$ measurement capability. Therefore, in this study, the needle probe method was chosen.

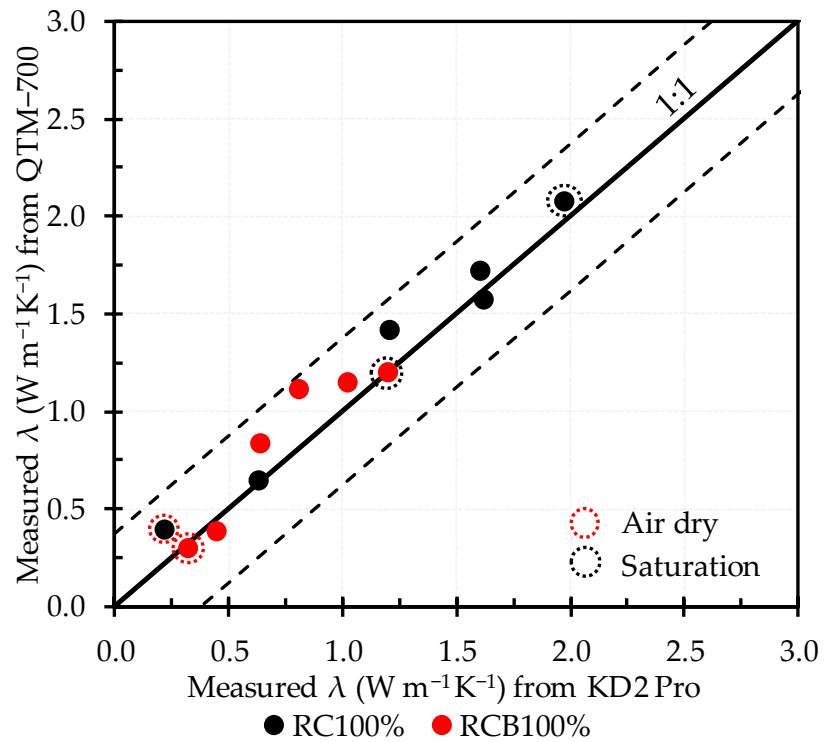

Figure 4. Comparison of measured $\lambda$ values by two different methods. The $95 \%$ confidence curves are indicated by broken lines.

The principle of heat transfer in porous materials is complicated due to the irregular microstructure [27]. Heat is transferred through these materials by thermal conduction in the solid phase, thermal conduction in the fluid phase (liquid or air), radiation, and convection of latent heat (vaporization) [7,27-29]. Of these, conduction and convection of latent heat play the most important role [29]; convection makes a large contribution when the gas-filled spaces (pore sizes) are over several millimeters [7,30], and radiation should be considered at a high temperature (above 200 degrees) [31]. All experiments were performed in a climate-controlled laboratory at $20{ }^{\circ} \mathrm{C}$ and relative humidity of $60 \%$; the pore sizes of all the tested samples were less than $1 \mathrm{~mm}$ (see Figure $3 b, d$ ). Therefore, convection and radiation can be neglected in this study, and heat transfer is considered conduction-dominant.

\subsection{Statistical Evaluation of the Model Prediction}

Three statistical indexes, i.e., the root mean square error (RMSE), bias, and Akaike's information criterion (AIC) [32,33], were used to calculate the statistical accuracy of the predictive thermal properties of the models described in the latter section. Of these, RMSE 
was used to evaluate the best overall fit compared with measured data, bias was used to evaluate the model overestimation (positive bias) or underestimation (negative bias) of measured thermal properties, and AIC was used to account for the number of model parameters, with smaller (or more negative) AIC indicating better model performance [34]. RMSE, bias, and AIC were calculated by the following equations:

$$
\begin{aligned}
& \mathrm{RMSE}=\sqrt{\frac{1}{n} \sum_{i=1}^{n} \Delta \lambda_{i}^{2}} \\
& \mathrm{bias}=\frac{1}{n} \sum_{i=1}^{n} \Delta \lambda_{i} \\
& \mathrm{AIC}=n\left[\ln (2 \pi)+\ln \left(\frac{\sum_{i=1}^{n} \Delta \lambda_{i}^{2}}{n-k}\right)+1\right]+k
\end{aligned}
$$

where $\Delta \lambda_{i}\left(\mathrm{~W} \mathrm{~m}^{-1} \mathrm{~K}^{-1}\right)$ is the difference between the $i$ th predicted and measured thermal conductivities, $n$ is the number of measurements, and $k$ is the number of model parameters.

\section{Model Development for Estimating Thermal Conductivity}

\subsection{Existing Models for Estimating Thermal Conductivity}

A variety of models have been used to predict the thermal conductivity of soils under varied moisture conditions. However, the number of studies conducted to predict the thermal conductivity of unbound aggregates, especially recycled aggregates, is very limited. In this study, a series of existing thermal conductivity models for soils were considered as listed below:

Lichtenecker [35] proposed the geometric mean model. Woodside and Messmer [31] used it for thermal conductivity prediction of two-phase porous material.

$$
\lambda=\lambda_{f}^{\phi} \lambda_{s}^{1-\phi}
$$

where $\lambda_{f}, \lambda_{s}\left(\mathrm{~W} \mathrm{~m} \mathrm{~m}^{-1} \mathrm{~K}^{-1}\right)$ are thermal conductivities of pore fluid and solid phases; $\phi\left(\mathrm{m}^{3} \mathrm{~m}^{-3}\right)$ is the total porosity of the soil. According to Beziat [36] and Zhang et al. [37], when soil consists of three phases (solid, water, and gas), thermal conductivity can be calculated as below:

$$
\lambda=\lambda_{s}^{1-\phi} \lambda_{w}^{\left(S_{r} / 100\right) \times \phi} \lambda_{a}^{\left[1-\left(S_{r} / 100\right)\right] \times \phi}
$$

where $\lambda_{s}$ and $\lambda_{w}$, and $\lambda_{a}\left(\mathrm{~W} \mathrm{~m}^{-1} \mathrm{~K}^{-1}\right)$ are the thermal conductivities of the solid phase, water, and air, respectively; $S_{r}(\%)$ is the degree of saturation:

$$
S_{r}=\frac{\theta}{\theta_{s}} \times 100
$$

where $\theta$ and $\theta_{s}\left(\mathrm{~m}^{3} \mathrm{~m}^{-3}\right)$ are the volumetric water content and the saturated volumetric water content. Note here that water is more thermally conductive than air by a factor of $>20$ $\left(\lambda_{w}=0.57 \mathrm{~W} \mathrm{~m}^{-1} \mathrm{~K}^{-1}\right.$ and $\lambda_{a}=0.025 \mathrm{~W} \mathrm{~m}^{-1} \mathrm{~K}^{-1}$ [38]). Thus, the higher the volumetric water content, the higher the apparent thermal conductivity.

The model that de Vries [38] proposed was also based on three phases, i.e., solid, water, and air, and had a different form. The thermal conductivity of all phases in combination with the volumetric fractions and the weighting factors were used to calculate thermal conductivity as the following equations:

$$
\lambda=\frac{\theta \lambda_{w}+k_{s} \sigma \lambda_{s}+k_{a} \varepsilon \lambda_{a p p}}{\theta+k_{s} \sigma+k_{a} \varepsilon}
$$




$$
\begin{gathered}
k_{s}=\frac{1}{3}\left\{\left[1+\left(\frac{\lambda_{s}}{\lambda_{w}}-1\right) g_{a}\right]^{-1}+\left[1+\left(\frac{\lambda_{s}}{\lambda_{w}}-1\right) g_{b}\right]^{-1}+\left[1+\left(\frac{\lambda_{s}}{\lambda_{w}}-1\right) g_{c}\right]^{-1}\right\} \\
k_{a}=\frac{1}{3}\left\{\left[1+\left(\frac{\lambda_{a p p}}{\lambda_{w}}-1\right) g_{a}\right]^{-1}+\left[1+\left(\frac{\lambda_{a p p}}{\lambda_{w}}-1\right) g_{b}\right]^{-1}+\left[1+\left(\frac{\lambda_{a p p}}{\lambda_{w}}-1\right) g_{c}\right]^{-1}\right\}
\end{gathered}
$$

where $\lambda_{w}$ and $\lambda_{s},\left(\mathrm{~W} \mathrm{~m}^{-1} \mathrm{~K}^{-1}\right)$ are the thermal conductivity of water and the solid phase, respectively; $\lambda_{\text {app }}\left(\mathrm{W} \mathrm{m}^{-1} \mathrm{~K}^{-1}\right)$ is the apparent thermal conductivity of the air-filled pore space, made up partly of normal heat conduction $\left(\lambda_{a}\right)$ and partly of vapor movement $\left(\lambda_{v}\right)$; $\theta, \sigma$, and $\varepsilon\left(\mathrm{m}^{3} \mathrm{~m}^{-3}\right)$ are the volumetric fractions of water, solids, and air, respectively; $k_{s}$ and $k_{a}$ are the weighting factors for the solid and air phases determined by $\lambda$ for each phase and geometric shape of the soil particles; and $g_{a}, g_{b}$, and $g_{c}$ represent the depolarization factor of the ellipsoid in the different directions, satisfying $g_{a}+g_{b}+g_{c}=1$. Farouki [7] suggested that $g_{a}=0.333-\frac{\varepsilon}{\phi}(0.333-0.035)$ and $g_{c}=1-2 g_{a}$.

Johansen [39] first introduced the concept of normalized thermal conductivity $\left(\lambda_{e}\right)$ :

$$
\lambda_{e}=\frac{\lambda-\lambda_{d r y}}{\lambda_{s a t}-\lambda_{d r y}}
$$

where $\lambda_{e}$ is normalized thermal conductivity, and $\lambda_{\text {sat }}$ and $\lambda_{d r y}\left(\mathrm{~W} \mathrm{~m}^{-1} \mathrm{~K}^{-1}\right)$ are thermal conductivities under full saturation and dry conditions, respectively. Johansen [39] proposed $\lambda_{e}$ as a function of $S_{\mathrm{r}}$ :

$$
\begin{gathered}
\text { for fine - grain materials : } \lambda_{e}=\log \left(S_{r} / 100\right)+1 \quad S_{r}>10 \% \\
\text { for coarse materials : } \lambda_{e}=0.7 \log \left(S_{r} / 100\right)+1 \quad S_{r}>5 \%
\end{gathered}
$$

The thermal conductivity at saturation was estimated by using the geometric mean equation:

$$
\lambda_{s a t}=\lambda_{w}^{\phi} \lambda_{s}^{1-\phi}
$$

where $\lambda_{w}$ and $\lambda_{s}\left(\mathrm{~W} \mathrm{~m}^{-1} \mathrm{~K}^{-1}\right)$ are the thermal conductivity of water and the solid phase, respectively; $\phi\left(\mathrm{m}^{3} \mathrm{~m}^{-3}\right)$ is the total porosity of the soil. Note that Equation (16) is equivalent to Equation (7). Thermal conductivity in dry conditions has an empirical form:

$$
\lambda_{d r y}=\frac{0.135 \rho_{d}+64.7}{\rho_{s}-0.947 \rho_{d}}
$$

Campbell [40] measured the thermal conductivity of a series of soils such as forest litter, silt loam soil, and sand to develop an empirical equation:

$$
\lambda=A+B \theta-(A-D) \exp \left[-(C \theta)^{E}\right]
$$

where $A, B, C, D$, and $E$ are parameters dependent on soil physical properties; $A=0.65-0.78\left(\rho_{\mathrm{d}} / 1000\right)+0.60\left(\rho_{\mathrm{d}} / 1000\right)^{2}, B=1.06\left(\rho_{\mathrm{d}} / 1000\right) \theta, C=1+2.6\left(1000 m_{\mathcal{C}}\right)^{-0.5}$, $D=0.03+0.10\left(\rho_{\mathrm{d}} / 1000\right)^{2}$, and $E=4$, where $\rho_{\mathrm{d}}\left(\mathrm{kg} \mathrm{m}^{-3}\right)$ is the dry bulk density and $m_{c}(\mathrm{~kg})$ is the clay mass fraction of the soil; $\theta\left(\mathrm{m}^{3} \mathrm{~m}^{-3}\right)$ is the volumetric water content.

Cote and Konrad [41] studied nearly 200 samples of unfrozen and frozen subbase and base materials with a variety of soil types. They proposed that normalized thermal conductivity is a function of the degree of saturation $\left(S_{r}\right)$ :

$$
\lambda_{e}=\frac{\kappa\left(S_{r} / 100\right)}{1+(\kappa-1)\left(S_{r} / 100\right)}
$$

where $\kappa$ is the parameter related to the soil type effect on the $\lambda_{e}-S_{r}$ relationship. They suggested that $\kappa$ is 4.6 for gravel and coarse sand; 3.55 for median and fine sand; and 1.9 
for silt and clay. Thermal conductivity of saturated soil was calculated by Equation (16). Thermal conductivity of dry soils was predicted:

$$
\lambda_{d r y}=\chi 10^{-\eta \phi}
$$

where $\chi$ and $\eta$ are the coefficients accounting for the effects of soil type and grain shape on the thermal conductivity of dry soils. $\chi=1.7$ and $\eta=1.8$ for well-graded gravels.

Lu et al. [42] measured thermal conductivity of 12 different soils such as sand, loam, and sandy loam and proposed the model for normalized thermal conductivity:

$$
\lambda_{e}=\exp \left\{F\left[1-\left(S_{r} / 100\right)^{F-1.33}\right]\right\}
$$

where $S_{r}(\%)$ is the degree of saturation; $F$ is a soil texture-dependent parameter, $F$ is suggested to be 0.96 and 0.27 for coarse and fine soils, respectively. Thermal conductivity of saturated soil was calculated by Equation (16). Lu et al. [42] presented a simple linear model for predicting the thermal conductivity of dry soils from the total porosity of the soil:

$$
\lambda_{d r y}=G-H \phi
$$

where $G$ and $H$ are the coefficients related to the thermal conductivity of dry soils. The suggested values are 0.56 and 0.51 .

\subsection{The New Models for Estimating Thermal Conductivity}

\subsubsection{Linear Model}

The volumetric water content $(\theta)$ is an important factor that significantly affects thermal conductivity of the samples. In this study, compacted samples contained high residual volumetric water content $\left(\theta_{r}\right)$ in air-dried conditions. Therefore, to develop the model for estimating $\lambda$ of tested samples with the change of $\theta$, we suggest that $\lambda$ should be a function of $\left(\theta-\theta_{r}\right)$. A linear model was expected for estimating $\lambda$ as:

$$
\lambda=a_{2}\left(\theta-\theta_{r}\right)+\lambda_{d r y}
$$

$\lambda_{d r y}$ can be calculated from $\sigma$ by a simple linear equation:

$$
\lambda_{d r y}=a_{1} \times \sigma+b_{1}
$$

where $a_{1}$ and $b_{1}$ are empirical parameters. We assumed $b_{1}$ is equal to the thermal conductivity of air, $b_{1}=\lambda_{a}=0.025 \mathrm{~W} \mathrm{~m}^{-1} \mathrm{~K}^{-1}$ [38]). Therefore, the linear model for thermal conductivity can be written as the equation:

$$
\lambda=a_{2}\left(\theta-\theta_{r}\right)+\left(a_{1} \sigma+b_{1}\right)
$$

\subsubsection{Simple Closed-Form Model}

In this study, simple closed-form models consisting of a parabolic segment (from $(0,0)$ to $(1,1)$ in the $x-y$ coordinate plane) for thermal conductivity were developed by using the concept of normalized thermal conductivity, $\lambda_{e}$ [39]. Previous studies proposed normalized thermal conductivity, $\lambda_{e}$, as a function of $S_{r}[39,41,42]$. In these, the $\lambda_{e}$ models of Johansen [39] and Lu et al. [42] are convex curves, while Cote and Konrad's $\lambda_{e}$ model [41] is a convex curve when $\mathrm{k}>1$ and a concave curve when $\kappa<1$. Cote and Konrad's $\lambda_{e}$ model seems to be more general than the other two models. Therefore, the simple closedform model for $\lambda_{e}$ in this study was developed based on Cote and Konrad's $\lambda_{e}$ model (Equation (19)) [41]. As mentioned above, in air-dried conditions, the tested samples contained a significant amount of water to make the $S_{r}$ values of tested samples large, which may not be expressed well by the previous $\lambda_{e}$ models. Thus, we incorporated the 
effective saturation, $S_{e}\left[S_{e}=\left(\theta-\theta_{r}\right) /\left(\theta_{s}-\theta_{r}\right)\right.$; Equation (1)], into the model development. The resulting new model for estimating $\lambda_{e}$ is shown by the equation below:

$$
\lambda_{e}=\frac{\kappa S_{e}}{1+(\kappa-1) S_{e}}
$$

where $\kappa$ is a material-dependent parameter.

Combining Equations (13) and (26), the new $\lambda$ model labeled the Johansen-CoteKonrad (J-CK) model can be obtained.

$$
\lambda=\frac{\kappa S_{e}}{1+(\kappa-1) S_{e}}\left(\lambda_{\text {sat }}-\lambda_{d r y}\right)+\lambda_{d r y}
$$

To estimate $\lambda_{\text {sat }}$ and $\lambda_{d r y}$, we applied two models: the geometric mean (GM) model [31] and the linear model. By applying the GM model for estimating $\lambda_{s a t}$ and $\lambda_{d r y}$, modified geometric mean equations were proposed to calculate $\lambda_{\text {sat }}$ and $\lambda_{d r y}$ of tested samples for not only single materials (i.e., RC100\%, RCB100\%, AAC100\%) but also mixtures (i.e., $\mathrm{RC} 80 \%+\mathrm{AAC} 20 \%, \mathrm{RC} 60 \%+\mathrm{AAC} 40 \%, \mathrm{RCB} 80 \%+\mathrm{AAC} 20 \%$, and $\mathrm{RCB} 60 \%+\mathrm{AAC} 40 \%)$ with the following equations:

$$
\begin{aligned}
& \lambda_{s a t}=\left(\lambda_{s 1}^{f} \times \lambda_{s 2}^{1-f}\right)^{\sigma} \times \lambda_{w}^{(1-\sigma)} \\
& \lambda_{d r y}=\left(\lambda_{s 1}^{f} \times \lambda_{s 2}^{1-f}\right)^{\sigma} \times \lambda_{a}^{(1-\sigma)}
\end{aligned}
$$

where $\lambda_{\mathrm{s} 1}$ and $\lambda_{\mathrm{s} 2}\left(\mathrm{~W} \mathrm{~m}^{-1} \mathrm{~K}^{-1}\right)$ are the thermal conductivity of the solid phase of aggregates 1 and 2 in the mixtures, respectively; $f$ is the proportion of aggregate 1 in the mixtures; and $\sigma\left(\mathrm{m}^{3} \mathrm{~m}^{-3}\right)$ is volumetric solid content. We assumed that $\lambda_{s}$ values of tested materials (RC, $\mathrm{RCB}$, and AAC) could be estimated from $\lambda_{\text {sat }}$ based on Equation (16) and are shown in

\begin{tabular}{|c|c|c|c|c|c|}
\hline Samples & $\begin{array}{c}\phi \\
\left(\mathrm{m}^{3} \mathrm{~m}^{-3}\right)\end{array}$ & $\begin{array}{c}1-\phi \\
\left(m^{3} m^{-3}\right)\end{array}$ & $\begin{array}{c}\lambda_{s a t} \\
\left(\mathrm{~W} \mathrm{~m} \mathbf{m}^{-1} \mathrm{~K}^{-1}\right)\end{array}$ & $\left(\mathrm{W} \mathrm{m}^{-1} \mathrm{~K}^{-1}\right)$ & $\begin{array}{c}\lambda_{s}(\mathrm{~b}) \\
\left(\mathrm{W} \mathrm{m}^{-1} K^{-1}\right)\end{array}$ \\
\hline AAC $100 \%$ & 0.70 & 0.30 & 0.935 & 0.57 & 2.933 \\
\hline RC100\% & 0.24 & 0.76 & 1.974 & 0.57 & 2.898 \\
\hline RCB100\% & 0.38 & 0.62 & 1.197 & 0.57 & 1.884 \\
\hline
\end{tabular}
Table 4 .

Table 4. Estimated thermal conductivity of solid $\left(\lambda_{s}\right)$ from saturation condition $\left(\lambda_{\text {sat }}\right)$ based on geometric mean model.

(a) Described by de Vries (1963), ${ }^{\text {(b) }}$ Calculated by Equation (16).

From Equations (27)-(29), a new model which is labeled the Johansen-Cote-Konrad geometric mean (J-CK-GM) model could be obtained by the equation below:

$$
\lambda=\frac{\kappa S_{e}}{1+(\kappa-1) S_{e}}\left[\left(\lambda_{s 1}^{f} \times \lambda_{s 2}^{1-f}\right)^{\sigma} \times \lambda_{w}^{(1-\sigma)}-\left(\lambda_{s 1}^{f} \times \lambda_{s 2}^{1-f}\right)^{\sigma} \times \lambda_{a}^{(1-\sigma)}\right]+\left(\lambda_{s 1}^{f} \times \lambda_{s 2}^{1-f}\right)^{\sigma} \times \lambda_{a}^{(1-\sigma)}
$$

Regarding the application of the linear model to estimate $\lambda_{s a t}$ and $\lambda_{d r y}, \lambda_{d r y}$ can be calculated by Equation (24), while $\lambda_{\text {sat }}$ can be calculated by substituting $\theta=\theta_{s}$ in Equation (25) to obtain:

$$
\lambda_{\text {sat }}=a_{2}\left(\theta_{s}-\theta_{r}\right)+\left(a_{1} \sigma+b_{1}\right)
$$

From Equations (24), (27) and (31), the new model, which is labelled the JohansenCote-Konrad linear (J-CK-L) model, can be written as the equation below:

$$
\lambda=\frac{\kappa S_{e}}{1+(\kappa-1) S_{e}} a_{2}\left(\theta_{s}-\theta_{r}\right)+\left(a_{1} \sigma+b_{1}\right)
$$




\section{Results and Discussion}

\subsection{Measured Thermal Conductivity and Heat Capacity}

Figures 5 and 6 showed the relationships between $\lambda, H C$, and $\theta$ of tested samples. The water states are also presented in the figures, with the boundary between capillary and hygroscopic regions assumed to be the sum of the maximum adsorbed water in fine and coarse aggregates [14]. The maximum volumetric water absorbed by coarse or fine aggregates can be calculated by $\theta_{a b s, c / f}=\left[m_{c / f} \times\left(w_{a b s, c / f} / 100\right)\right] /(1000 \mathrm{~V})$, where $m_{c / f}$ is the mass of coarse or fine aggregates in the tested sample $(\mathrm{kg}), w_{a b s, c / f}$ is the water absorption of coarse or fine aggregates $(\mathrm{kg} / \mathrm{kg}$ in $\%)$, and $V$ is the volume of the sample $\left(\mathrm{m}^{3}\right)$. The maximum volumetric absorbed water by coarse and fine aggregates for the tested materials is shown in Table 1.

Hygroscopic $:$\begin{tabular}{l} 
Capillary + gravitational \\
\hdashline
\end{tabular}
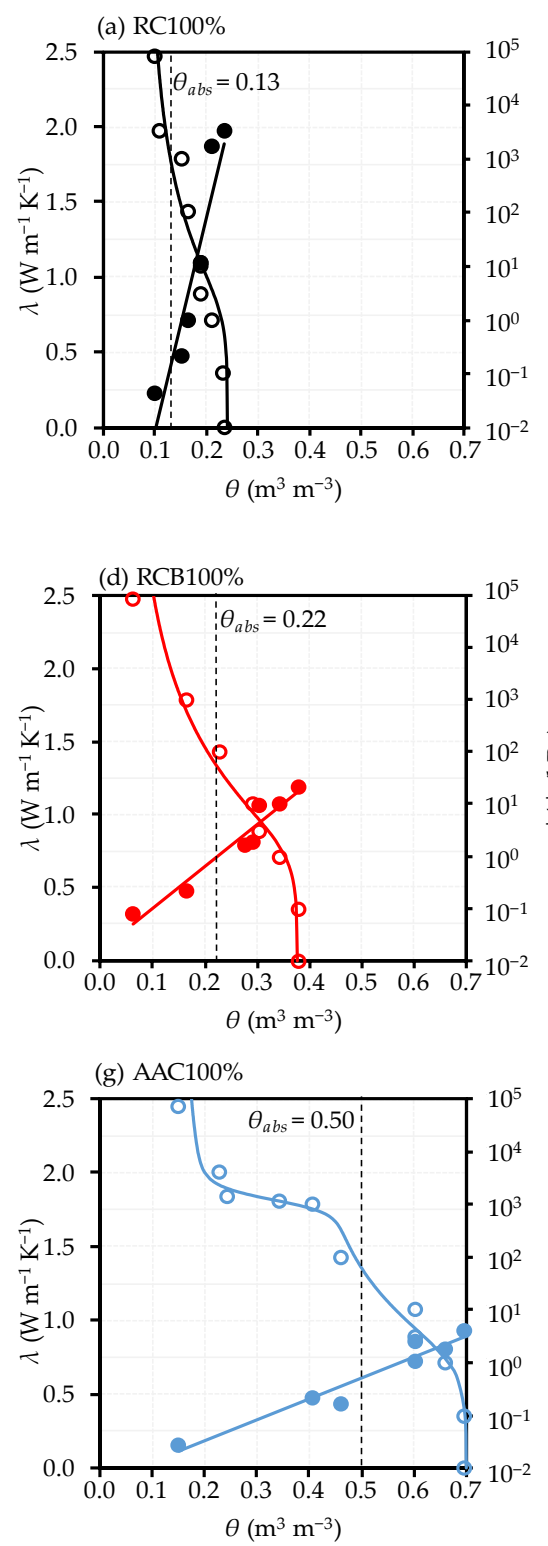
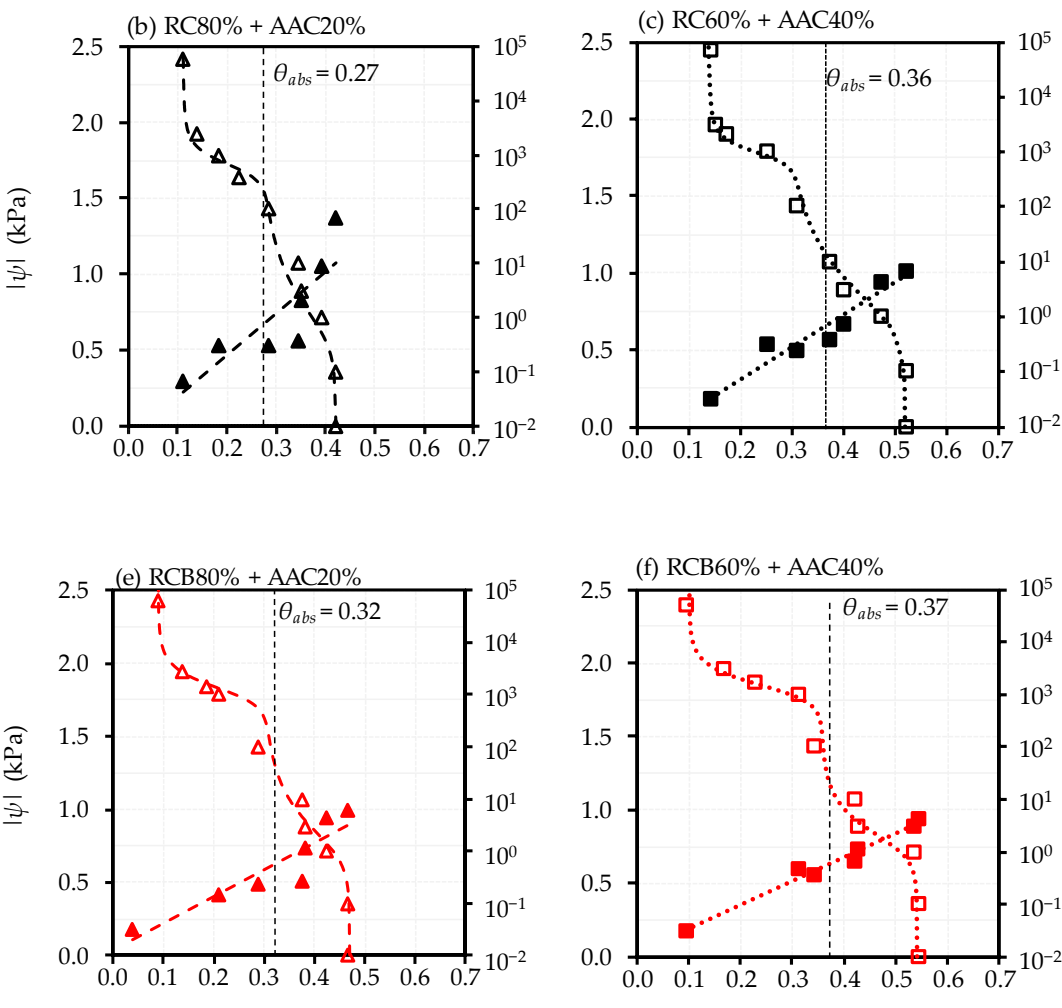

- $\mathrm{RC} 100 \% \Delta \mathrm{RC} 80 \%+\mathrm{AAC} 20 \%-\mathrm{RC} 60 \%+\mathrm{AAC} 40 \% \cdot \mathrm{RCB} 100 \% \Delta \mathrm{RCB} 80 \%+\mathrm{AAC} 20 \% \square \mathrm{RCB} 60 \%+\mathrm{AAC} 40 \% \bullet \mathrm{AAC} 100 \%$

Figure 5. Thermal conductivity as a function of volumetric water content and water retention curves of tested samples. The filled points present the data of thermal conductivity, and the unfilled points present the data of water retention curves. 

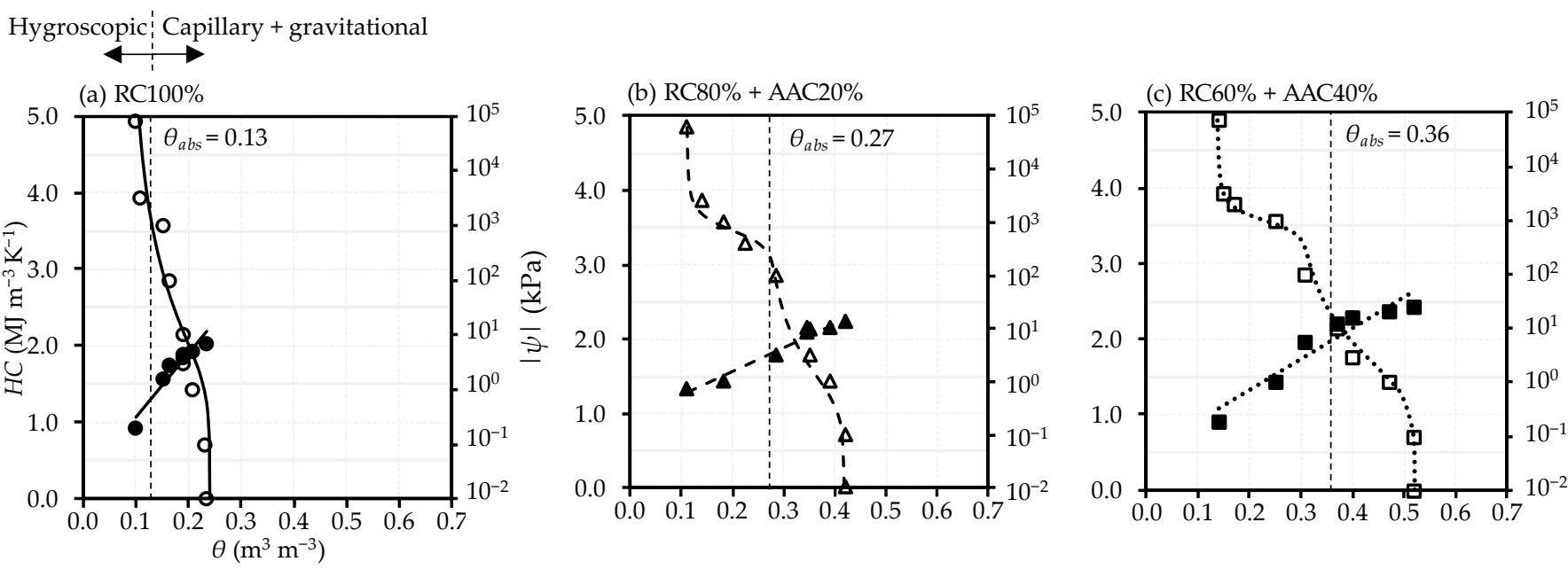

(d) $\mathrm{RCB} 100 \%$
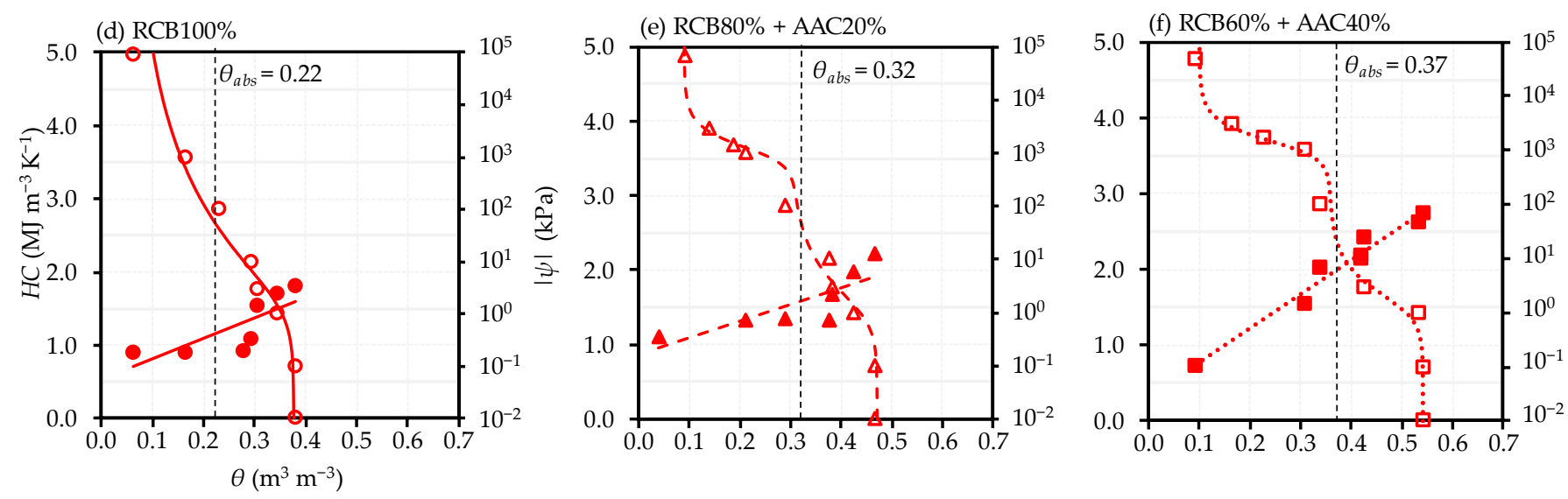

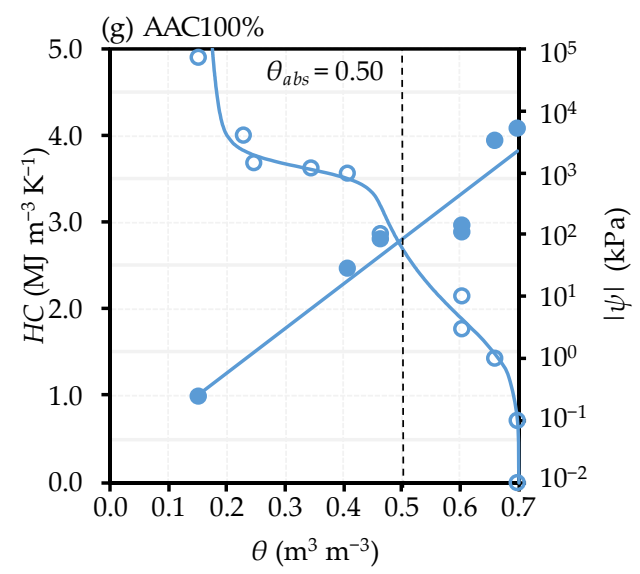

- $\mathrm{RC} 100 \% \Delta \mathrm{RC} 80 \%+\mathrm{AAC} 20 \%-\mathrm{RC} 60 \%+\mathrm{AAC} 40 \% \cdot \mathrm{RCB} 100 \% \Delta \mathrm{RCB} 80 \%+\mathrm{AAC} 20 \%$ RCB $60 \%+\mathrm{AAC} 40 \% \cdot \mathrm{AAC} 100 \%$

Figure 6. Heat capacity as a function of volumetric water content and water retention curves of tested samples. The filled points present the data of heat capacity, and the unfilled points present the data of water retention curves.

Figure 5 shows that the $\lambda$ values of all tested samples increased with the increase in $\theta$ for all tested samples. This can be explained by the water bridge effect. When the water content in samples increased, the particles were surrounded by the water films that bridge the gaps between the particles. These water films tended to increase the effective contact area between the particles, which caused the increase in the thermal 
conductivity [43-46]. As noted above, water has a significantly higher thermal conductivity than $\operatorname{air}\left(\lambda_{w}=0.57 \mathrm{~W} \mathrm{~m}^{-1} \mathrm{~K}^{-1}\right.$ and $\lambda_{a}=0.025 \mathrm{~W} \mathrm{~m}^{-1} \mathrm{~K}^{-1}$ [38]); when $\theta$ increases, water displaces air, leading to an increase in the thermal conductivity of the sample. Turning to the comparison of tested materials, at the same $\theta$ value, $\mathrm{RC}$ had the highest $\lambda$ value followed by RCB and AAC. This may be due to the difference in the water absorption capacity of materials. AAC and RCB had a higher water absorption capacity than RC (see Table 1), which resulted in the water films surrounding the AAC and RCB particles being thinner than the water films surrounding the RC particles at the same $\theta$ value. Hence, AAC and RCB had lower thermal conductivity than RC.

Figure 6 shows the heat capacity $(H C)$ of the tested samples as a function of $\theta$. The $H C$ values of all tested samples increased linearly with the increase in the $\theta$ values. In addition, it can be seen that the materials with a higher water holding capacity usually have a higher heat capacity in saturation conditions. This may be because water has a very high volumetric heat capacity $\left(4.18 \mathrm{MJ} \mathrm{m}^{-3} \mathrm{~K}^{-1}[38]\right)$.

Thermal conductivity and heat capacity in air-dried conditions $\left(\lambda_{d r y}\right.$ and $\left.H C_{d r y}\right)$ of the tested samples are shown in Figure 7 . The predictive models from previous studies for $\lambda_{d r y}$ and $H C_{d r y}$ were also plotted. $\lambda_{d r y}$ and $H C_{d r y}$ depend on a variety of factors such as particle shape, dry density, total porosity, and volumetric solid content $[38,39,41,42,47]$. Both $\lambda_{d r y}$ and $H C_{d r y}$ tended to increase as the volumetric solid content $(\sigma)$ increased, similar to the trend of previous studies. However, the measured data were not expressed well by the previous predictive models. The measured data were fitted by using Equation (24) with $a_{1}=0.35$ and $b_{1}=0.025$. The regression line for $H C_{d r y}-\sigma$ relationship is shown in Figure $7 \mathrm{~b}$.
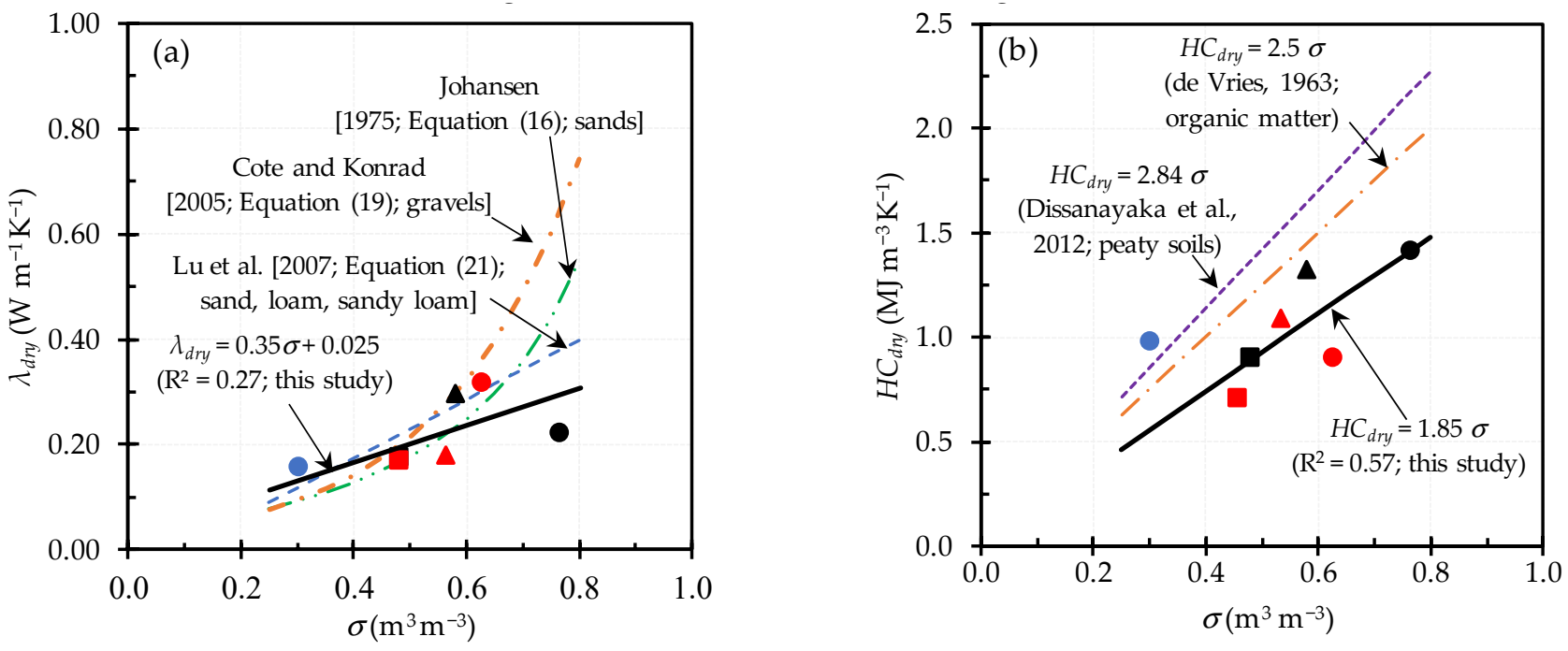

- $\mathrm{RC} 100 \% \Delta \mathrm{RC} 80 \%+\mathrm{AAC} 20 \%$ - RC60\% + AAC40\% $-\mathrm{RCB} 100 \% \Delta \mathrm{RCB} 80 \%+\mathrm{AAC} 20 \%$ - $\mathrm{RCB} 60 \%+\mathrm{AAC} 40 \% \cdot \mathrm{AAC} 100 \%$

Figure 7. Measured $\lambda_{d r y}$ and $H C_{d r y}$ of tested samples as a function of volumetric solid content, $\sigma$.

Figure 8 showed the $\lambda$ and $H C$ values of the tested samples as linear functions of $\left(\theta-\theta_{r}\right)$. The proposed linear model for $\lambda$ based on Equation (25) gave good regressions $\left(R^{2}>0.81\right)$ for the tested samples, except for the RC $80 \%+$ AAC $20 \%$ sample $\left(R^{2}=0.71\right)$. The regression lines for $H C$ values correlated with $\left(\theta-\theta_{r}\right)$ of the tested samples are shown in the figure with relatively high values of $R^{2}(\geq 0.71)$. 

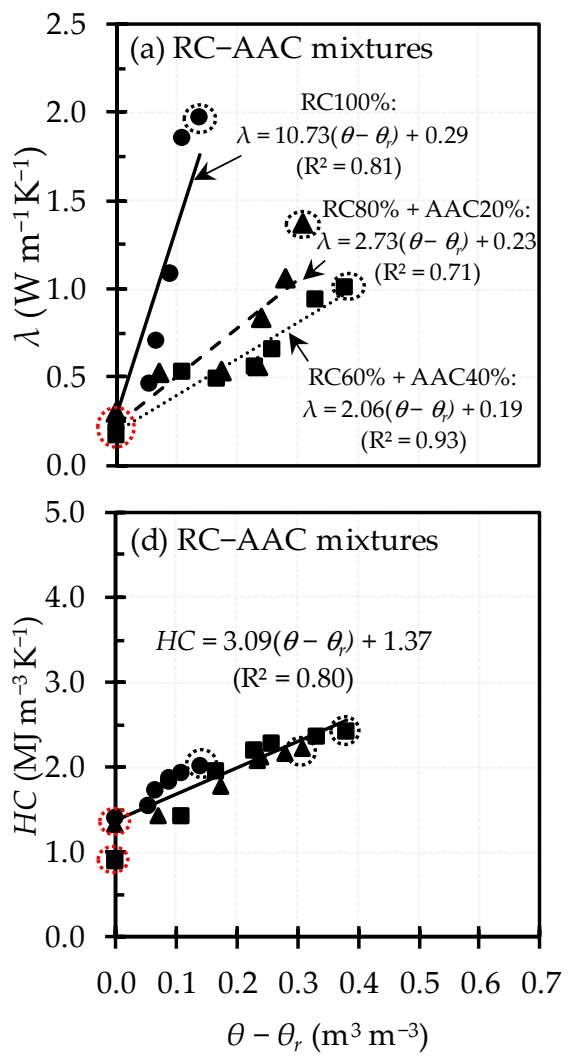
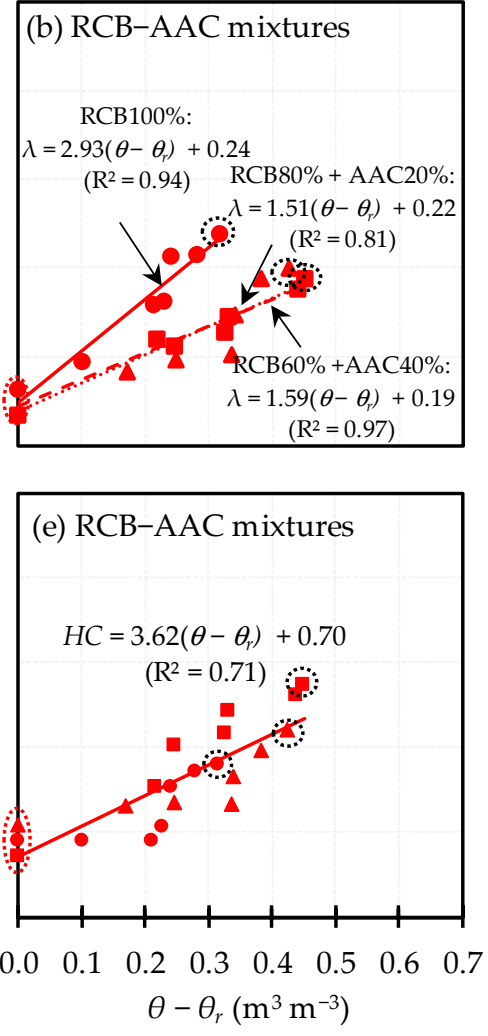
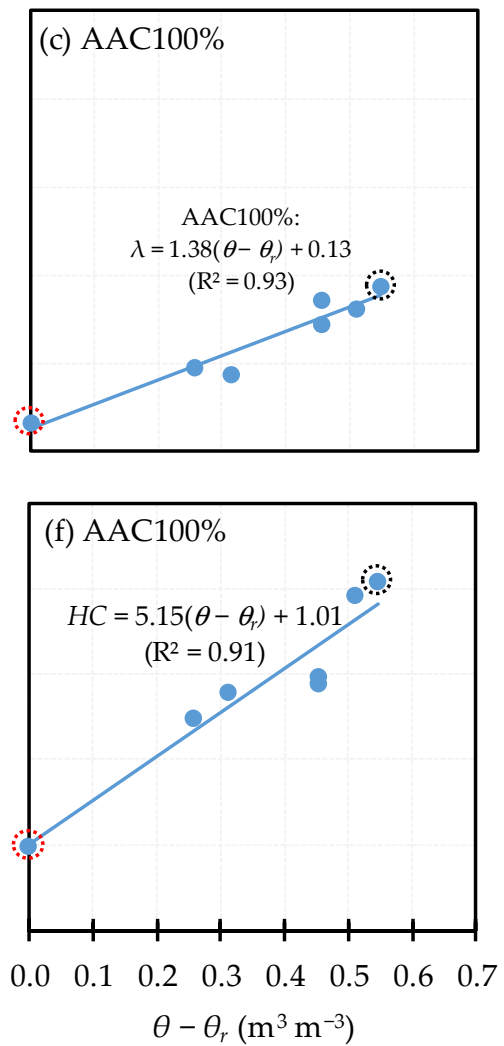

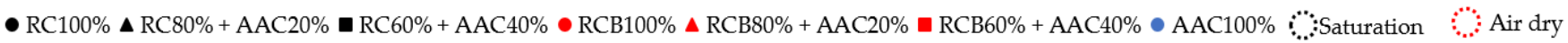

Figure 8. Measured $\lambda$ and $H C$ as a function of $\left(\theta-\theta_{r}\right)$.

Figure 9 shows the relationships between $\lambda_{e}$ and $S_{e}$ for the tested samples, sands [48], silt loam, and silty clay loam [42]. It is clearly seen that the new $\lambda_{e}$ model performed very well not only in data measured in this study but also in data sets from previous studies. The $\mathrm{R}^{2}$ values for the $\lambda_{e}-S_{e}$ relationship based on Equation (26) for each data set ranged from 0.91 to 0.97 .

Figure 10 indicates the effects of material type, particle size, and gradation on $\kappa$ values. In Figure $10 a, \kappa$ values are plotted as a function of median diameter $\left(D_{50}\right)$. The $\kappa$ values of the tested samples using recycled materials in this study were less than 1 , while those of natural materials (i.e., sands, silty loam, and silty clay loam) were more than 1 . This means that $\lambda_{e}$ values of recycled materials increase less rapidly than those of natural materials with increasing $S_{e}$. This may be because recycled materials had higher water absorption capacity than natural materials, which caused water films between particles of recycled materials to form at a higher water content than natural materials. $\kappa$ values tended to increase with increasing $D_{50}$ for natural materials, while $\kappa$ values of recycled materials fluctuated with the increasing $D_{50}$. Turning to the effect of gradation, the relationship between $\kappa$ values and the coefficient of uniformity $\left(C_{u} ; C_{u}=D_{60} / D_{10}\right.$; where $D_{60}$ and $D_{10}$ $(\mathrm{mm})$ are particle diameters at which $60 \%$ and $10 \%$ of particles, respectively are smaller) are shown in Figure $10 \mathrm{~b}$. The $\kappa$ values of samples decreased with increasing $C_{u}$, and the regression line was fitted: $\kappa=0.73\left[\log \left(C_{u}\right)\right]^{-0.67}\left(R^{2}=0.75\right)$. 

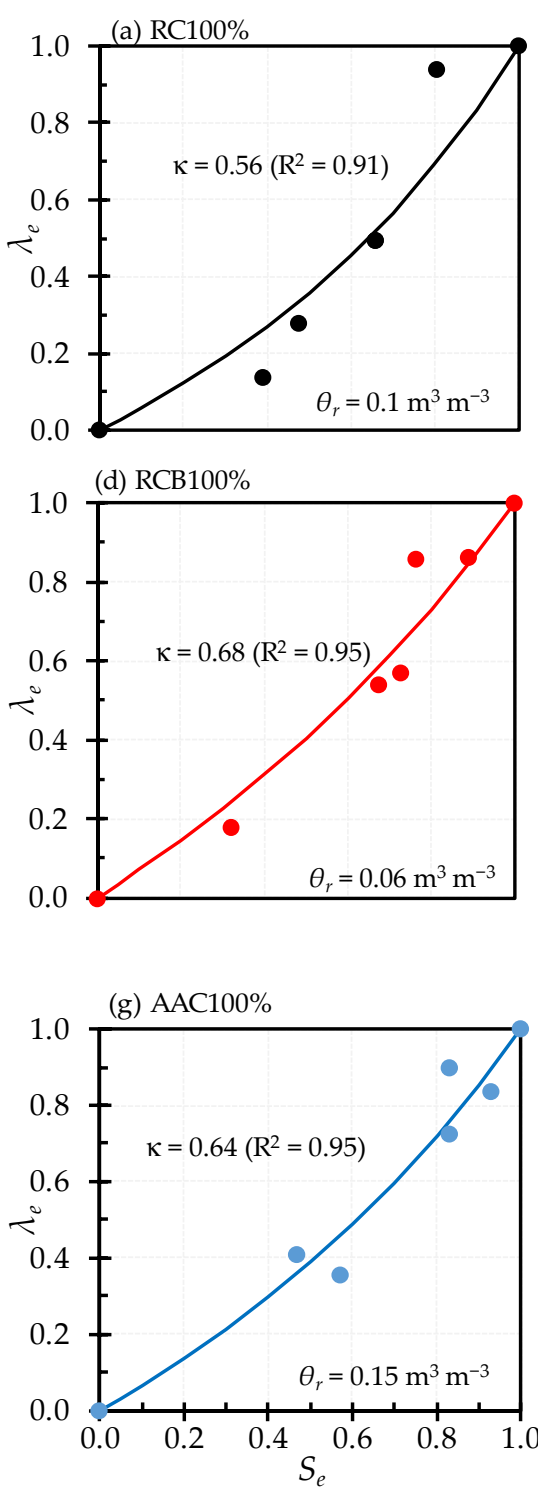

Data from previous studies

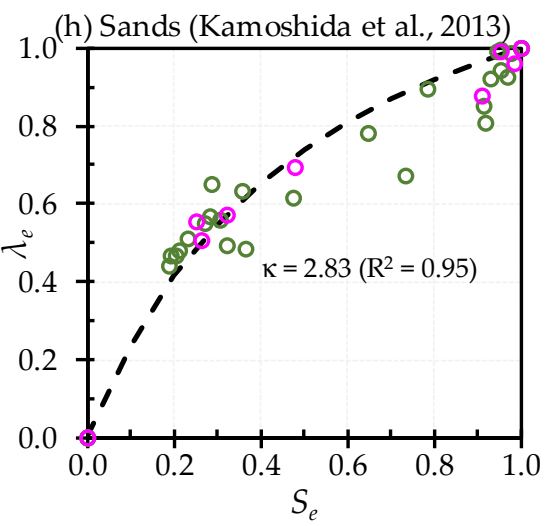

- $\mathrm{RC} 100 \%$

- RCB $100 \%$

- AAC $100 \%$

$\Delta$ Silty loam (Lu et al., 2007) (b) $\mathrm{RC} 80 \%+\mathrm{AAC} 20 \%$

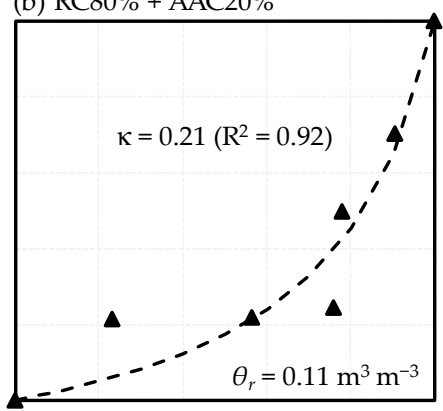

(e) $\mathrm{RCB} 80 \%+\mathrm{AAC} 20 \%$

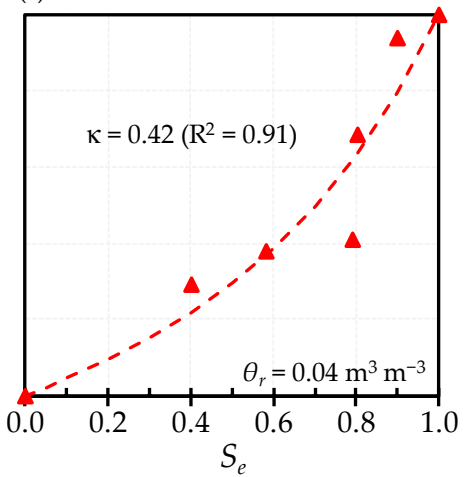

(c) $\mathrm{RC} 60 \%+\mathrm{AAC} 40 \%$

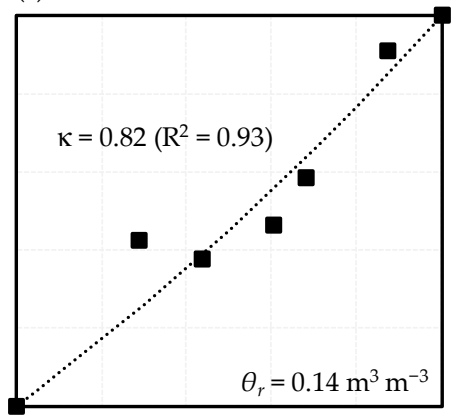

(f) $\mathrm{RCB} 60 \%+\mathrm{AAC} 40 \%$

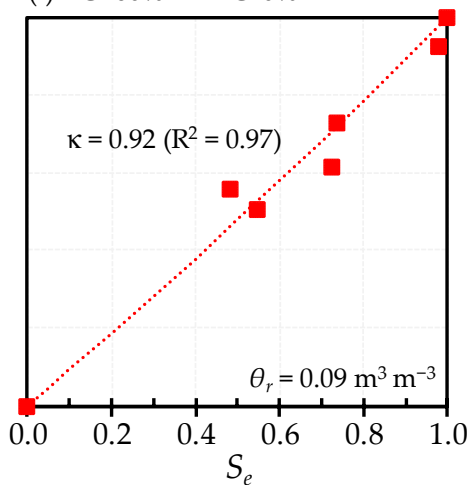

(i) Silty loam (Lu et al., 2007)

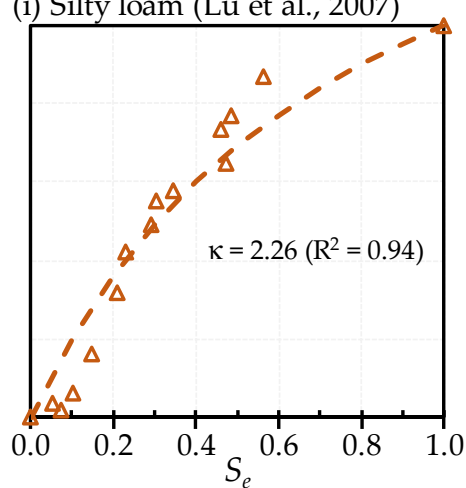

$\Delta \mathrm{RC} 80 \%+\mathrm{AAC} 20 \%$

$\triangle \mathrm{RCB} 80 \%+\mathrm{AAC} 20 \%$

o Narita sand (Kamoshida et al., 2013)

$\Delta$ Silty clay loam (Lu et al., 2007) (j) Silty clay loam (Lu et al., 2007)

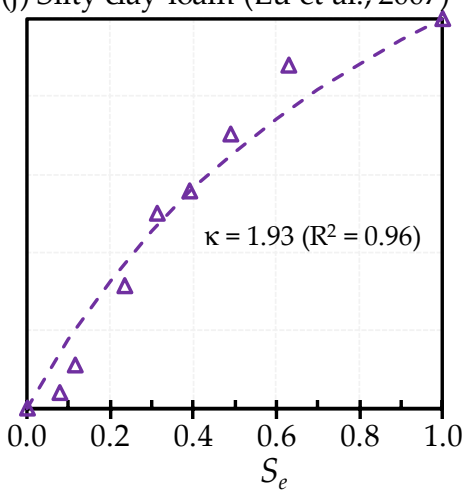

Figure 9. Normalized thermal conductivity, $\lambda_{e}$, as a function of effective saturation, $S_{e}$. 


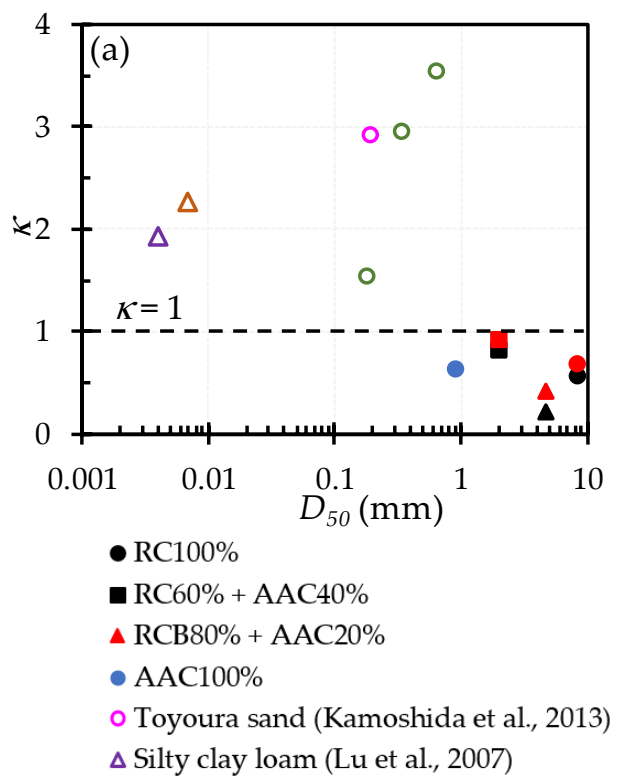

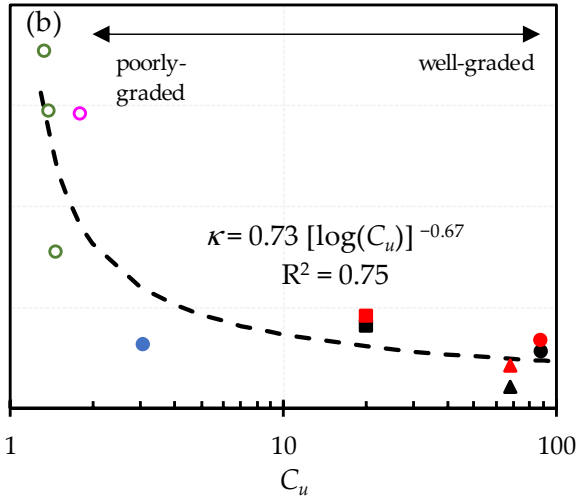

$\Delta \mathrm{RC} 80 \%+\mathrm{AAC} 20 \%$

- RCB100\%

- RCB $60 \%+\mathrm{AAC} 40 \%$

- Narita sand (Kamoshida et al., 2013)

$\Delta$ Silty loam (Lu et al., 2007)

Figure 10. $\kappa$ as a function of (a) $D_{50}$ and (b) $C_{u}$.

\subsection{Performance of the Predictive Models for Thermal Conductivity}

Figure 11 shows scatter plot comparisons of predicted and measured $\lambda$ for the new models in this study and the previous models. The statistical indexes (RMSE, bias, AIC) of the models are listed in Table 5. Looking at Figure 11, most of the previous models showed worse model performance except for the Woodside and Messmer model [31] for RCB-AAC mixtures and AAC $100 \%$ samples. In contrast, the new models in this study performed well; most of the predicted values were correlated with the measured values ranging from 1:4/3 to 4/3:1 for all tested samples except for the J-CK-GM model for RC100\% and RC $80 \%+$ AAC20\% samples. The RMSE and AIC values of the new models were significantly lower than those of the previous models (see Table 5), in which the J-CK-L model had the lowest RMSE and AIC. Therefore, it can be concluded that the new models are more suitable to describe the thermal conductivity of recycled aggregates and mixtures than previous models.

Table 5. Test of predictive thermal conductivity $(\lambda)$ models against measured data.

\begin{tabular}{|c|c|c|c|c|c|c|}
\hline \multirow{2}{*}{ Models } & \multicolumn{3}{|c|}{ All Tested Samples } & \multicolumn{3}{|c|}{ Mixtures } \\
\hline & RMSE & Bias & AIC & RMSE & Bias & AIC \\
\hline Woodside and Messmer (1961; Equation (8)) & 0.34 & -0.18 & 42.9 & 0.25 & -0.15 & 11.8 \\
\hline de Vries (1963; Equation (10)) & 0.45 & -0.32 & 78.6 & 0.37 & -0.29 & 40.5 \\
\hline Johansen (1975; Equations (13), (15)-(17)) & 0.47 & -0.34 & 75.1 & 0.37 & -0.30 & 33.7 \\
\hline Campbell (1985; Equation (18)) & 0.46 & 0.34 & 68.0 & 0.34 & 0.27 & 24.7 \\
\hline Conte and Konrad (2005; Equations (13), (16), (19) and (20)) & 0.49 & -0.36 & 80.4 & 0.39 & -0.32 & 36.6 \\
\hline Lu et al. (2007; Equations (13), (16), (21) and (22)) & 0.45 & -0.33 & 70.9 & 0.35 & -0.29 & 31.7 \\
\hline Linear model (this study, Equation (25)) & 0.14 & -0.02 & -46.7 & 0.12 & -0.01 & -33.1 \\
\hline J-CK-GM model (this study, Equation (30)) & 0.25 & -0.13 & 17.9 & 0.21 & -0.15 & 7.1 \\
\hline J-CK-L model (this study, Equation (32)) & 0.14 & 0.06 & -48.9 & 0.12 & 0.06 & -32.7 \\
\hline
\end{tabular}


(a) Woodside and Messmer (1961)

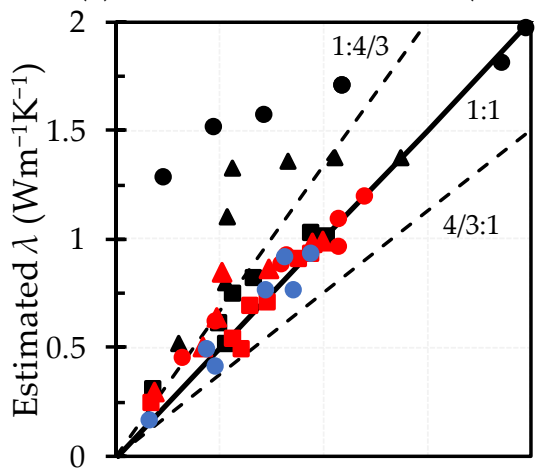

(d) Campbell (1985)

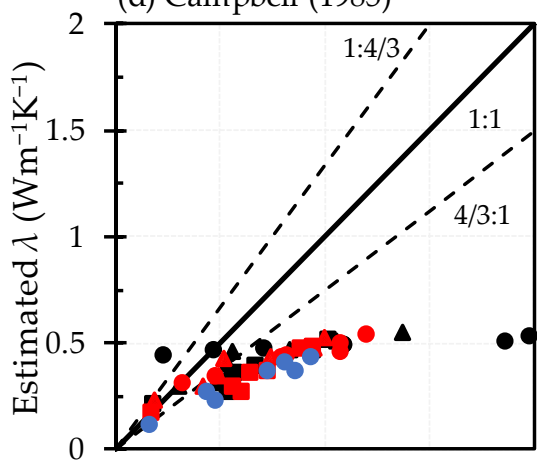

(g) Linear model (this study)

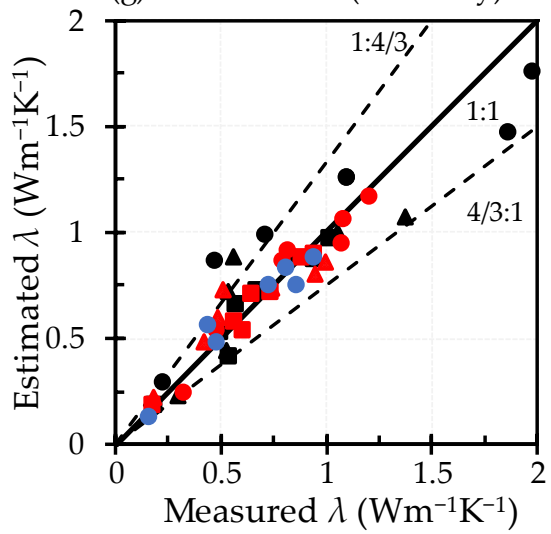

(b) de Vries (1963)

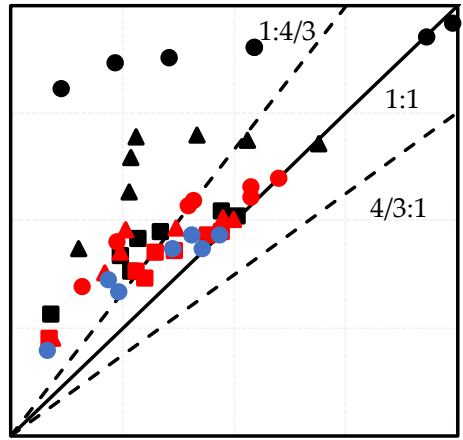

(e) Cote and Konrad (2005)

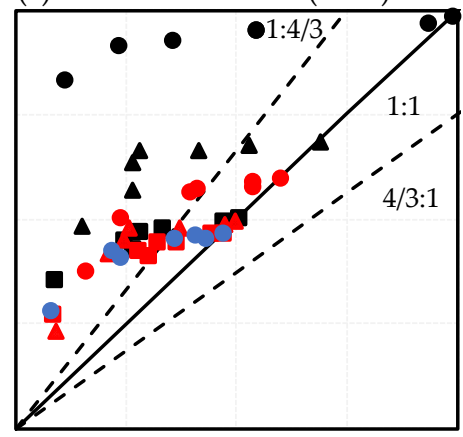

(h) J-CK-GM model (this study)

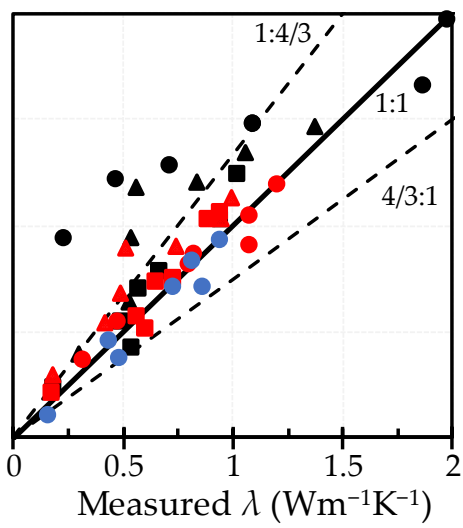

(c) Johansen (1975)

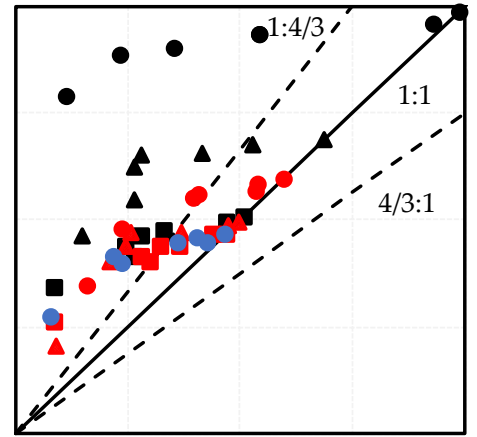

(f) Lu et al. (2007)

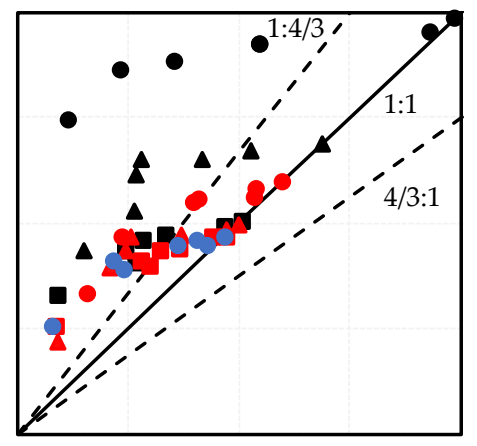

(i) J-CK-L model (this study)

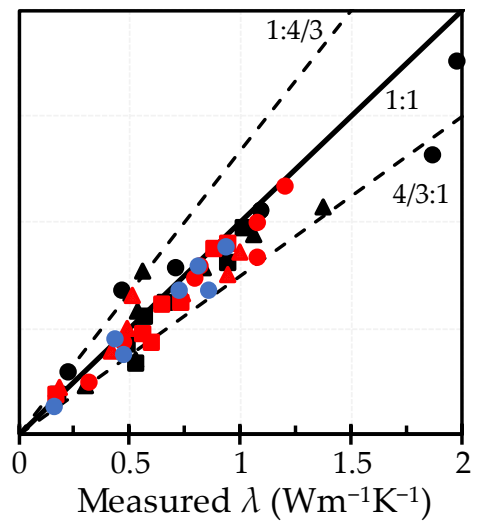

- $\mathrm{RC} 100 \% \Delta \mathrm{RC} 80 \%+\mathrm{AAC} 20 \% \square \mathrm{RC} 60 \%+\mathrm{AAC} 40 \% \bullet \mathrm{RCB} 100 \% \Delta \mathrm{RCB} 80 \%+\mathrm{AAC} 20 \%-\mathrm{RCB} 60 \%+\mathrm{AAC} 40 \% \bullet \mathrm{AAC} 100 \%$

Figure 11. Scatterplot comparison of estimated and measured $\lambda$ values of tested samples.

\section{Conclusions}

The measurement of thermal conductivity and heat capacity of recycled aggregates from concrete, clay brick, and their mixtures with autoclaved aerated concrete grains was carried out in the laboratory during the drying process from saturation to air-dried conditions. The results showed that, when compacted as described in this study, both $\lambda$ and $H C$ of recycled aggregates increased linearly with the increase in volumetric water content. The existing predictive models for thermal conductivity indicated a need for improvement. Two simple closed-form models (labelled J-CK-GM and J-CK-L) were newly refined based on the relationship between normalized thermal conductivity $\left(\lambda_{e}\right)$ and effective saturation $\left(S_{e}\right)$. The refined models estimated sufficiently well the measured data of tested samples, and the J-CK-L model especially had the best performance among tested thermal conductivity models. Because the J-CK-L model with a single variable of 
$\kappa$ adopted measured data from different mixed proportions of recycled concrete and clay brick aggregate and their mixtures with AAC grains, the model would be useful for quick assessment of the thermal conductivity of roadbed materials and for evaluating the heat balance to mitigate urban heat islands.

Author Contributions: Conceptualization, H.N.T., K.K. and H.G.N.; methodology, H.N.T. and K.K.; software, H.N.T. and H.G.N.; validation, K.K.; formal analysis, H.N.T. and K.K.; investigation, resources, and data curation, H.N.T. and K.K.; writing - original draft preparation, H.N.T.; writingreview and editing, T.K., T.S., P.M., H.G.N. and K.K.; visualization, H.N.T.; supervision, T.K., T.S., P.M., and K.K.; project administration, H.G.N. and K.K.; funding acquisition, K.K. All authors have read and agreed to the published version of the manuscript.

Funding: This research was supported by the project of Japan Science and Technology Agency (JST), Japan International Cooperation Agency (JICA) on Science, and Technology Research Partnership for Sustainable Development (SATREPS) (no. JPMJSA1701).

Institutional Review Board Statement: Not applicable.

Informed Consent Statement: Not applicable.

Data Availability Statement: The data presented in this study are available on request from the corresponding author.

Acknowledgments: We thank Akira Kato, a former Researcher at Saitama University, and Van Nam Pham, a student at Saitama University, for their help in the process of sample preparation and measurement in the laboratory.

Conflicts of Interest: The authors declare no conflict of interest.

\section{Abbreviations and Symbols}

\begin{tabular}{|c|c|}
\hline $\mathrm{AAC}$ & Autoclaved aerated concrete \\
\hline AIC & Akaike's information criterion \\
\hline CDW & Construction and demolition waste \\
\hline LA & Los Angeles abrasion \\
\hline RC & Recycled concrete \\
\hline $\mathrm{RCB}$ & Recycled clay brick \\
\hline RMSE & Root mean square error \\
\hline WRCs & Water retention curves \\
\hline$A, B, C, D, E$ & Parameters dependent on physical properties of the soil (Equation (18)) (-) \\
\hline$a_{1}, b_{1}$ & Empirical parameters in the linear model used for estimating $\lambda_{d r y}$ (Equation (24)) (-) \\
\hline$a_{2}$ & Parameter in linear model (Equation (25)) (-) \\
\hline$C^{*}$ & Specific moisture capacity (-) \\
\hline$C_{u}$ & Coefficient of uniformity (-) \\
\hline$D_{50}$ & Mean particle size (mm) \\
\hline F & Soil texture dependent parameter in Equation (21) (-) \\
\hline$f$ & Proportion of aggregate in the mixtures \\
\hline$G, H$ & Coefficients in Equation (22) (-) \\
\hline$g_{a}, g_{b}, g_{c}$ & Depolarization factor of the ellipsoid in different directions (-) \\
\hline $\mathrm{HC}$ & Heat capacity $\left(\mathrm{MJ} \mathrm{m}^{-3} \mathrm{~K}^{-1}\right)$ \\
\hline$H C_{d r y}$ & Heat capacity at air dried $\left(\mathrm{MJ} \mathrm{m}^{-3} \mathrm{~K}^{-1}\right)$ \\
\hline$k$ & Number of model parameters (-) \\
\hline$k_{a}$ & Weighting factors for the air phase (-) \\
\hline$k_{S}$ & Weighting factors for the solid phase (-) \\
\hline$m_{c}$ & Clay mass fraction of the soil $(\mathrm{kg})$ \\
\hline$r$ & Equivalent pore radius $(\mu \mathrm{m})$ \\
\hline$S_{e}$ & Effective saturation (-) \\
\hline$S_{r}$ & Degree of saturation (\%) \\
\hline$w_{a b s}$ & Water absorption capacity (\%) \\
\hline
\end{tabular}




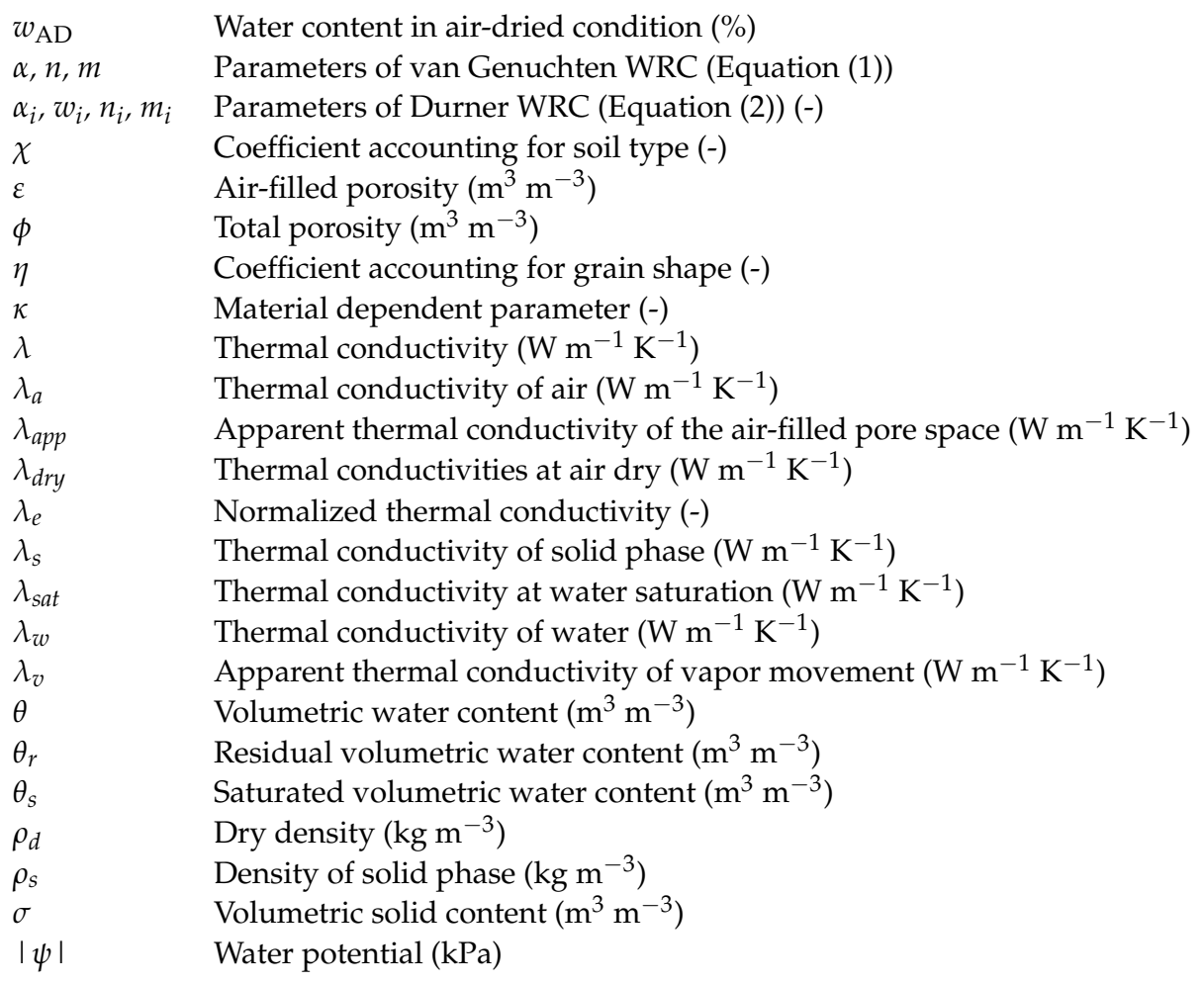

\section{Appendix A}

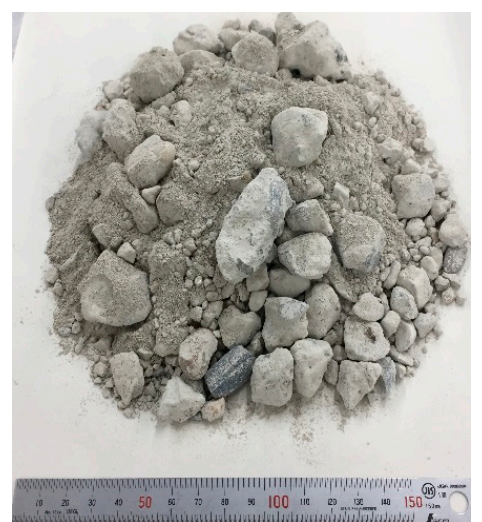

(a) $\mathrm{RC} 100 \%$

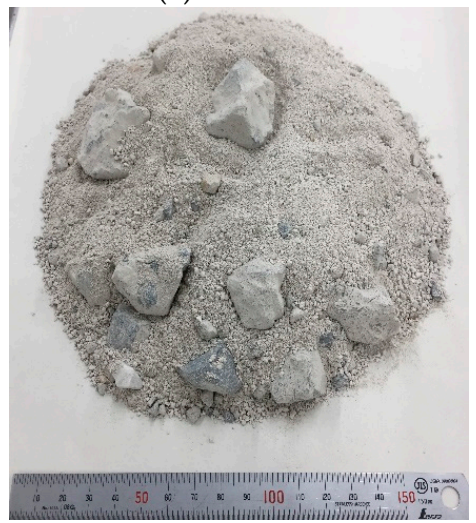

(c) $\mathrm{RC} 60 \%+\mathrm{AAC} 40 \%$

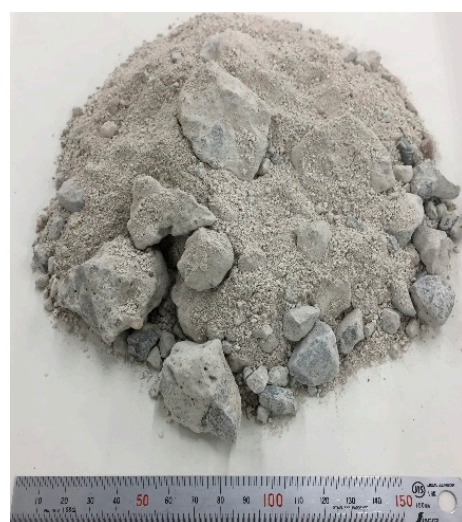

(b) $\mathrm{RC} 80 \%+\mathrm{AAC} 20 \%$

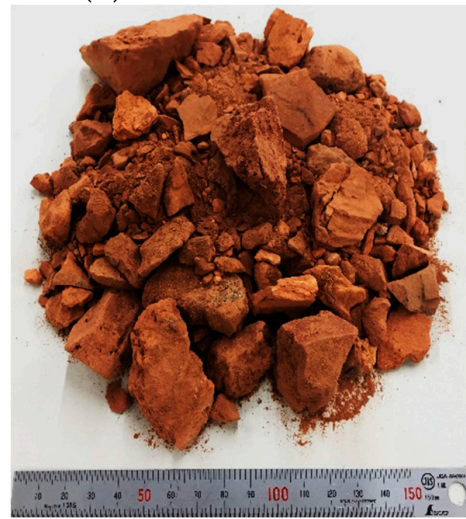

(d) $\mathrm{RCB} 100 \%$

Figure A1. Cont. 


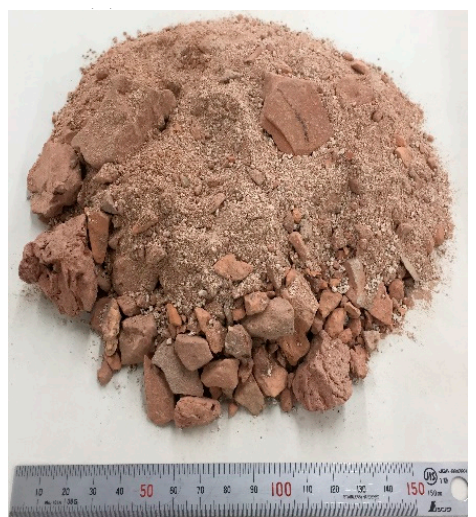

(e) $\mathrm{RCB} 80 \%+\mathrm{AAC} 20 \%$

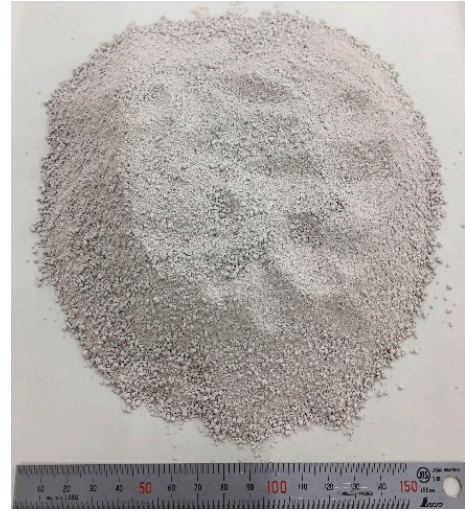

(g) AAC100\%

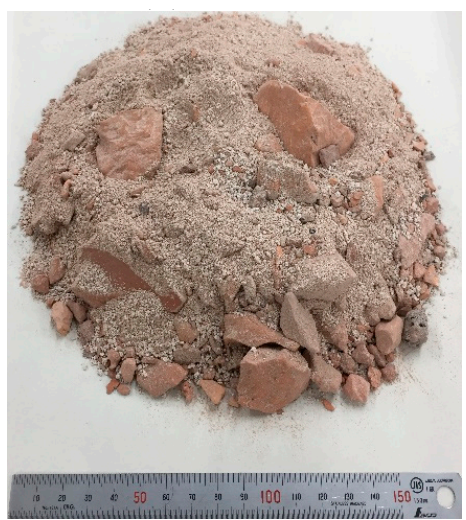

(f) $\mathrm{RCB} 60 \%+\mathrm{AAC} 40 \%$

Figure A1. Tested samples.

Figure A2 compares the thermal conductivity between the tested samples and other materials such as lightweight concrete [49,50], pervious concrete [51], and concrete [52] in air-dried (Figure A2a) and saturated conditions (Figure A2b). The $\lambda_{d r y}$ values of most tested samples were lower than those of concrete and lightweight concrete and higher than those of pervious concrete at the same dry density value except for $\lambda_{d r y}$ value of RC100\% sample. In the saturated conditions, $\lambda_{\text {sat }}$ values of tested samples were higher than those of pervious concrete.

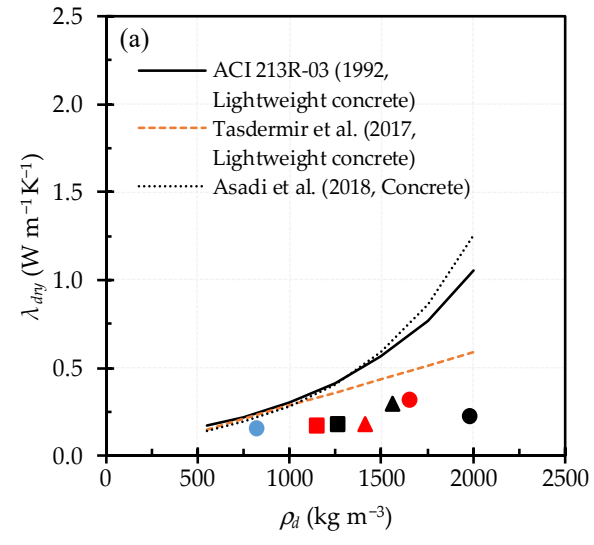

- $\mathrm{RC} 100 \%$

- RCB100\%

- $\mathrm{RC} 80 \%+\mathrm{AAC} 20 \%$

- $\mathrm{AAC} 100 \%$

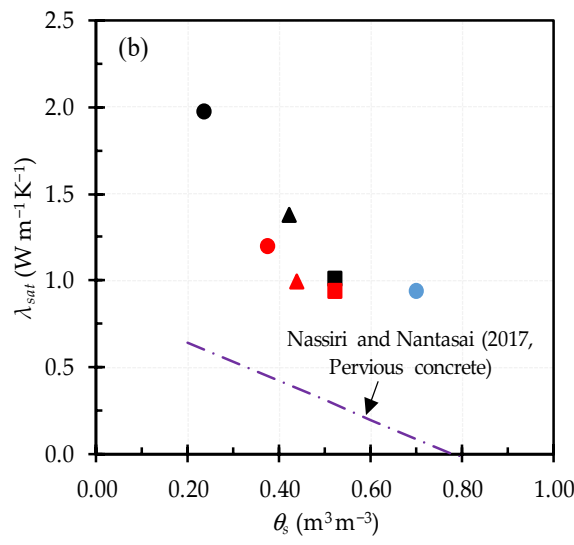

- $\mathrm{RC} 60 \%+\mathrm{AAC} 40 \%$

- RCB $60 \%$ + AAC40\%

Figure A2. Comparison of measured thermal conductivities of tested samples in this study with those for (a) lightweight and normal concrete in air dried condition and (b) pervious concrete in saturated condition. 


\section{References}

1. Nguyen, H.G.; Nguyen, T.D.; Nghiem, H.T.; Tran, V.C.; Kato, A.; Matsuno, A.; Isobe, Y.; Kawasaki, M.; Kawamoto, K. Current management condition and waste composition characteristics of construction and demolition waste landfills in hanoi of vietnam. Sustainability 2021, 13, 10148. [CrossRef]

2. Hoang, N.H.; Ishigaki, T.; Kubota, R.; Yamada, M.; Kawamoto, K. A review of construction and demolition waste management in Southeast Asia. J. Mater. Cycles Waste Manag. 2020, 22, 315-325. [CrossRef]

3. Hoang, T.; Nguyen, V.P.; Thai, H.N. Use of coal ash of thermal power plant for highway embankment construction. In CIGOS 2019, Innovation for Sustainable Infrastructure. Lecture Notes in Civil Engineering; Ha-Minh, C., Dao, D., Benboudjema, F., Derible, S., Huynh, D., Tang, A., Eds.; Springer: Singapore, 2020; Volume 54, pp. 433-439. [CrossRef]

4. Deloitte. Resource Efficient Use of Mixed Wastes Improving Management of Construction and Demolition Waste. Available online: https:/ / op.europa.eu/en/publication-detail/-/publication/78e42e6c-d8a6-11e7-a506-01aa75ed71a1/language-en (accessed on 15 January 2022).

5. Ministry of Natural Resources and Environment (MONRE). Report on National Environment: Solid Waste; Ministry of Natural Resources and Environment: Hanoi, Vietnam, 2011. (In Vietnamese)

6. Nguyen, V.T.; Tong, T.K.; Dang, T.T.H.; Tran, T.V.N.; Nguyen, H.G.; Nguyen, T.D.; Isobe, Y.; Ishigaki, T.; Kawamoto, K. Current status of construction and demolition waste management in Vietnam: Challenges and opportunities. Int. J. GEOMATE 2018, 15, 23-29. [CrossRef]

7. Farouki, O.T. Thermal Properties of Soils; Defense Tactical Information Center: Hanover, NH, USA, 1981.

8. Chen, S.X. Thermal conductivity of sands. Heat Mass Transf. 2008, 44, 1241-1246. [CrossRef]

9. Deng, H.; Deng, D.; Du, Y.; Lu, X. Using lightweight materials to enhance thermal resistance of asphalt mixture for cooling asphalt pavement. Adv. Civ. Eng. 2019, 2019, 1-10. [CrossRef]

10. Huang, Q.; Qian, Z.; Hu, J.; Zheng, D. Evaluation of stone mastic asphalt containing ceramic waste aggregate for cooling asphalt pavement. Materials 2020, 13, 2964. [CrossRef] [PubMed]

11. Pham, V.N.; Kato, A.; Nguyen, H.G.; Nguyen, V.T.; Phan, Q.M.; Kawamoto, K. Gas transport parameters of recycled concrete and clay brick aggregate blended with autoclaved aerated concrete grains. Int. J. GEOMATE 2021, 20, 93-100. [CrossRef]

12. Poon, C.S.; Chan, D. Feasible use of recycled concrete aggregates and crushed clay brick as unbound road sub-base. Constr. Build. Mater. 2006, 20, 578-585. [CrossRef]

13. Thai, H.N.; Kato, A.; Nguyen, H.G.; Nguyen, T.D.; Tong, T.K.; Nguyen, V.T.; Uchimura, T.; Maki, T.; Kawamoto, K. Effects of particle size and type of aggregate on mechanical properties and environmental safety of unbound road base and subbase materials: A Literature Review. Int. J. GEOMATE 2021, 20, 148-157. [CrossRef]

14. Thai, H.N.; Nguyen, T.D.; Nguyen, V.T.; Nguyen, H.G.; Kawamoto, K. Characterization of compaction and CBR properties of recycled concrete aggregates for unbound road base and subbase materials in Vietnam. J. Mater. Cycles Waste Manag. 2022, 24, 34-48. [CrossRef]

15. TCVN 8859:2011. Aggregate Bases and Subbases of Pavement Structure-Material, Construction, and Acceptance. Vietnam, 2011. Available online: https://thuvienphapluat.vn/TCVN/Xay-dung/Tieu-chuan-Viet-Nam-TCVN-8859-2011-lop-mongcap-phoi-da-dam-trong-ket-cau-ao-904056.aspx (accessed on 15 January 2022). (In Vietnamese)

16. TCVN 8857:2011. Natural Aggregate for Road Pavement Layers Specification for Material, Construction and Acceptance. Vietnam, 2011. Available online: https:/ / thuvienphapluat.vn/TCVN/Giao-thong/TCVN-8857-2011-Lop-ket-cau-ao-duong-o-to-bangcap-phoi-thien-nhien-904969.aspx (accessed on 15 January 2022). (In Vietnamese)

17. TCVN 12790:2020. Soils, Aggregates for Transport Infrastructure-Proctor Compaction Test. Vietnam, 2020. Available online: https:/ / thuvienphapluat.vn/TCVN/Giao-thong/TCVN-12790-2020-Dat-da-dam-dung-trong-cong-trinh-giao-thongDam-nen-Proctor-918809.aspx (accessed on 15 January 2022). (In Vietnamese)

18. ASTM D1557-12; ASTM D1557 Standard Test Methods for Laboratory Compaction Characteristics of Soil Using Modified Effort $\left(56,000 \mathrm{ft}-\mathrm{lbf} / \mathrm{ft} 3\left(2,700 \mathrm{kN}-\mathrm{m} / \mathrm{m}^{3}\right)\right)$. ASTM International: West Conshohocken, PA, USA, 2012. [CrossRef]

19. Van Genuchten, M.T. A closed-form equation for predicting the hydraulic conductivity of unsaturated soils. Soil Sci. Soc. Am. J. 1980, 44, 892-898. [CrossRef]

20. Durner, W. Hydraulic conductivity estimation for soils with heterogeneous pore structure. Water Resour. Res. 1994, 30, 211-223. [CrossRef]

21. Seki, K. SWRC fit-A nonlinear fitting program with a water retention curve for soils having unimodal and bimodal pore structure. Hydrol. Earth Syst. Sci. Discuss. 2007, 4, 407-437. [CrossRef]

22. Brutsaert, W. Probability laws for pore size distribution. Soil Sci. 1966, 101, 85-92. [CrossRef]

23. Schober, G. Porosity in autoclaved aerated concrete (AAC): A review on pore structure, types of porosity, measurement methods and effects of porosity on properties. Cem. Wapno Bet. 2011,39-43.

24. Chen, G.; Li, F.; Jing, P.; Geng, J.; Si, Z. Effect of pore structure on thermal conductivity and mechanical properties of autoclaved aerated concrete. Materials. 2021, 14, 339. [CrossRef]

25. Nagihara, S.; Hedlund, M.; Zacny, K.; Taylor, P.T. Improved data reduction algorithm for the needle probe method applied to in-situ thermal conductivity measurements of lunar and planetary regoliths. Planet. Space Sci. 2014, 92, 49-56. [CrossRef] 
26. Yuksel, N. The Review of Some Commonly Used Methods and Techniques to Measure the Thermal Conductivity of Insulation Materials. In Insulation Materials in Context of Sustainability; Almusaed, A., Almssad, A., Eds.; IntechOpen: London, UK, 2016; pp. 113-140. [CrossRef]

27. Tavman, I.H. Effective thermal conductivity of granular porous materials. Int. Commun. Heat Mass Transf. 1996, 23, 169-176. [CrossRef]

28. Hermansson, Å.; Charlier, R.; Collin, F.; Erlingsson, S.; Laloui, L.; SršenSr, M. Heat transfer in soils. In Water in Road Structures, Geotechnical, Geological and Earthquake Engineering; A. Dawson, Ed.; Springer: Dordrecht, The Netherlands, 2009; Volume 5, pp. 69-79. [CrossRef]

29. Jury, W.A.; Horton, R. Soil Physics, 6th ed.; John Wiley and Sons Inc.: New York, NY, USA, 2004.

30. Woodside, W. Calculation of the thermal conductivity of porous media. Canada J. Phys. 1958, 36, 815-823. [CrossRef]

31. Woodside, W.; Messmer, J.H. Thermal conductivity of porous media. I. Unconsolidated sands. J. Appl. Phys. 1961, 32, 1688-1699. [CrossRef]

32. Akaike, H. Information theory and an extension of the maximum likelihood principle. In Proceedings of the 2nd International Symposium on Information Theory; Petrov, B.N., Csaki, F., Eds.; Akademiai Kiado: Budapest, Hungary, 1973; pp. $267-281$.

33. Carrera, J.; Neuman, S.P. Estimation of aquifer parameters under transient and steady state conditions: 1. Maximum likelihood method incorporating prior information. Water Resour. Res. 1986, 22, 199-210. [CrossRef]

34. Minasny, B.; Mcbratney, A.B.; Bristow, K.L. Comparison of different approaches to the development of pedotransfer functions for water-retention curves. Geoderma 1999, 93, 225-253. [CrossRef]

35. Lichteneker, K. The electrical conductivity of periodic and random aggregates. Phys. Zeitschrift 1926, $27,115$.

36. Beziat, A.; Dardaine, M.; Mouche, E. Measurements of the thermal conductivity of clay-sand and clay-graphite mixtures used as engineered barriers for high-level radioactive waste disposal. Appl. Clay Sci. 1992, 6, 245-263. [CrossRef]

37. Zhang, N.; Wang, Z. Review of soil thermal conductivity and predictive models. Int. J. Therm. Sci. 2017, 117, 172-183. [CrossRef]

38. de Vries, D.A. Thermal properties of soils. In Physics of the Plant Environment; van Wijk, W.R., Ed.; John Wiley \& Sons: New York, NY, USA, 1963; pp. 210-235.

39. Johansen, O. Thermal Conductivity of Soils. Ph.D. Thesis, University of Trondheim, Trondheim, Norway, 1977.

40. Campbell, G.S. Soil physics with BASIC. Transport Models for Soil-Plant Systems; Elsevier Science B. V.: Amsterdam, The Netherlands, 1985.

41. Côté, J.; Konrad, J.M. Thermal conductivity of base-course materials. Can. Geotech. J. 2005, 42, 61-78. [CrossRef]

42. Lu, S.; Ren, T.; Gong, Y.; Horton, R. An improved model for predicting soil thermal conductivity from water content at room temperature. Soil Sci. Soc. Am. J. 2007, 71, 8-14. [CrossRef]

43. Sepaskhah, A.R.; Boersma, L. Thermal conductivity of soils as a function of temperature and water content. Soil Sci. Soc. Am. J. 1979, 43, 439-444. [CrossRef]

44. Becker, B.R.; Misra, A.; Fricke, B.A. Development of correlations for soil thermal conductivity. Int. Commun. Heat mass Transf. 1992, 19, 59-68. [CrossRef]

45. Hamamoto, S.; Moldrup, P.; Kawamoto, K.; Komatsu, T. Excluded-volume expansion of Archie's law for gas and solute diffusivities and electrical and thermal conductivities in variably saturated porous media. Water Resour. Res. 2010, 46, 1-14. [CrossRef]

46. Dong, Y.; McCartney, J.S.; Lu, N. Critical review of thermal conductivity models for unsaturated soils. Geotech. Geol. Eng. 2015, 33, 207-221. [CrossRef]

47. Dissanayaka, S.H.; Hamamoto, S.; Kawamoto, K.; Komatsu, T.; Moldrup, P. Thermal properties of peaty soils: Effects of liquid-phase impedance factor and shrinkage. Vadose Zo. J. 2012, 11, vzj2011.0092. [CrossRef]

48. Kamoshida, T.; Hamamoto, S.; Kawamoto, K.; Sakaki, T.; Komatsu, T. Thermal properties of sands at variably-saturated condition: Effectsof particle size and shape, and quartz content. J. Jpn. Soc. Soil Phys. 2013, 16, 11-16. (In Japanese) [CrossRef]

49. ACI Committee 213R-03. Guide for Structural Lightweight-Aggregate Concrete; American Concrete Institute: Farmington Hills, MI, USA, 1992

50. Tasdemir, C.; Sengul, O.; Tasdemir, M.A. A comparative study on the thermal conductivities and mechanical properties of lightweight concretes. Energy Build. 2017, 151, 469-475. [CrossRef]

51. Nassiri, S.; Nantasai, B. Thermal conductivity of pervious concrete for various porosities. ACI Mater. J. 2017, 114, 265-271. [CrossRef]

52. Asadi, I.; Shafigh, P.; Bin Abu Hassan, Z.F.; Mahyuddin, N.B. Thermal conductivity of concrete-A review. J. Build. Eng. 2018, 20, 81-93. [CrossRef] 